\title{
PALEOECOLOGY OF AN EARLY EOCENE MAMMALIAN FAUNA FROM PALEOSOLS IN THE CLARKS FORK BASIN, NORTHWESTERN WYOMING (U.S.A.)
}

\author{
DALE A. WINKLER ${ }^{1}$ \\ Museum of Paleontology, The University of Michigan, Ann Arbor, MI 48109 (U.S.A.)
}

(Received November 30, 1982; revised version accepted April 20, 1983)

\section{ABSTRACT}

Winkler, D. A., 1983. Paleoecology of an early Eocene mammalian fauna from paleosols in the Clarks Fork Basin, northwestern Wyoming (U.S.A.). Palaeogeogr., Palaeoclim. matol., Palaeoecol., 43: 261-298.

The paleoecology and depositional history of an early Eocene vertebrate assemblage dominated by small mammals is analyzed at a richly fossiliferous locality in the Willwood Formation, northwestern Wyoming. Systematic surface sampling using a quadrat net, screen washing, and quarrying of fresh sediment show that all vertebrate material in these fluvial deposits is contained in dark gray mudstones representing the A horizons of paleosols. Seven such paleosols occur in $22 \mathrm{~m}$ of stratigraphic section. The fauna includes 34 species of mammals, and also birds, reptiles, amphibians, fishes and gastropods. All vertebrate fossil material is fragmented, but it shows no evidence of transportation or current sorting. Surface weathering and possibly carnivore activity are responsible for the fragmentation and for an overabundance of dense and compact skeletal elements.

Detailed surface collections were made to obtain multiple samples from the different bone beds (paleosols). Principle component analysis shows that differences in the type and abundance of fossils from the various collecting areas are related to differences between contained bone beds, not differences along single bone beds. One paleosol has a red $B$ horizon and six have an orange $B$ horizon. The gray-over-red colored paleosol is faunally distinct from gray-over-orange paleosols. It contains the only specimens of two large, archaic mammals, and no very small mammalian taxa.

Cluster analysis on the occurrence of vertebrate taxa is used to define subsets of the fauna that may represent animals living in different habitats. Separate clusters are formed by a group of the most common terrestrial herbivorous mammals and the crocodilian Allognathosuchus, and by a group of small, possibly arboreal herbivores and carnivores.

The relative abundance of each mammalian species was initially calculated from a sample representing a minimum of 300 individual animals collected from the surface. The surface sample is dominated by mammals that are medium-sized for the fauna. Screen washing yields a greater relative abundance of very small mammals than was found on the surface. This indicates that the surface sample is biased against small forms. Corrected relative abundances based on both surface and washing samples show that the fauna is dominated numerically by very small mammals (one multituberculate species and several insectivores). Screen washing of fresh matrix is the best means of sampling a locality for paleoecological purposes.

\footnotetext{
${ }^{1}$ Present address: Department of Geological Sciences, The University of Texas at Austin,
} Austin, TX 78712 (U.S.A.). 


\section{INTRODUCTION}

Many pioneering studies in taphonomy have focused on Neogene faunas dominated by large mammals, especially ungulates (Shotwell, 1963; Voorhies, 1969; Behrensmeyer, 1975). A few previous taphonomical studies have dealt with small mammals (Dodson, 1973; Mellett, 1974), but the literature casts doubt on their usefulness in paleoecology (Behrensmeyer, 1975). Another aspect of earlier investigations in paleoecology is their reliance upon using the depositional interpretation of different lithologies in a sequence preserving vertebrates in order to recognize habitat differences (Olson, 1962; Shotwell, 1963; Behrensmeyer, 1975).

This study presents an analysis of a Paleogene fauna dominated by mammals less than five kilograms in weight. Since less is known about the habits of these animals (they have few modern counterparts) more can be learned by taphonomical analysis than for many Neogene forms. The numerous fossil-bearing zones in this locality represent only one depositional environment, namely flood plain paleosols. Habitat relationships are analyzed spatially along single time planes in a limited area, and temporally, between paleosols, using the co-occurrence of vertebrate taxa. It is suggested that differences in habitat can be determined independently from obvious differences in sedimentary setting.

Fossils from thin-bedded flood plain deposits are likely to provide the most reliable basis for community reconstruction because bones are subjected to little mechanical destruction or selective transport by size in this environment (Voorhies, 1970, p. 455). Thus, thin-bedded flood plain deposits are probably the best sedimentary setting on which to study paleoecological problems involving small mammals (Bown and Kraus, 1981b). The assemblage described here provides an opportunity to analyze faunal relationships and relative faunal abundances in a flood plain community.

The objective of this study is a detailed analysis of the taphonomic origin and paleoecology of mammalian fossils at one representative early Eocene locality. More specifically, an attempt is made to: (1) interpret the ecological and depositional environment of fossils using a collecting program designed to accurately locate and describe the individual lithologies containing fossil mammals; (2) determine, as accurately as possible, the relative abundances of the mammalian taxa in the fossil assemblage; and (3) compare different collecting techniques to find the best means of sampling a locality for paleoecological purposes.

The study area is in the Clark's Fork drainage basin, which is in the northwestern part of the larger Bighorn Basin, in northwestern Wyoming. The Bighorn Basin is one of a series of structural basins in the Rocky Mountain foreland. This basin received extensive fluvial sedimentation throughout the early Cenozoic, shed from rising mountain ranges that surrounded the basin (Mackin, 1937). One of the most complete sequences of Paleocene through early Eocene (Puercan through Wasatchian) mammalian faunas in the world is preserved here (Gingerich et al., 1980b). 
The Bighorn Basin is surrounded on the west, south, and east by the Beartooth, Absaroka, Owl Creek and Bighorn Mountains, and it is open to the north. Both late Paleocene and early Eocene sedimentary rocks are well exposed in extensive badlands (Van Houten, 1944). This study was conducted in the summer of 1978 at a new fossil locality in the Willwood Formation in the drainage area known as Big Sand Coulee. The Big Sand Coulee drainage is bounded by Polecat Bench on the east, Ralston Flats on the south and Badland Hills on the west (Fig.1).

The Willwood Formation consists of an alternating series of variegated mudstones and sandstones which are exposed throughout much of the Bighorn Basin (Van Houten, 1944; Neasham and Vondra, 1972). It is distinguished from the underlying Fort Union (or Polecat Bench) Formation chiefly by the occurrence of red beds. Fossil mammalian localities in the Willwood Formation are delimited areally by outcrop distribution and stratigraphically by bounding sandstones.

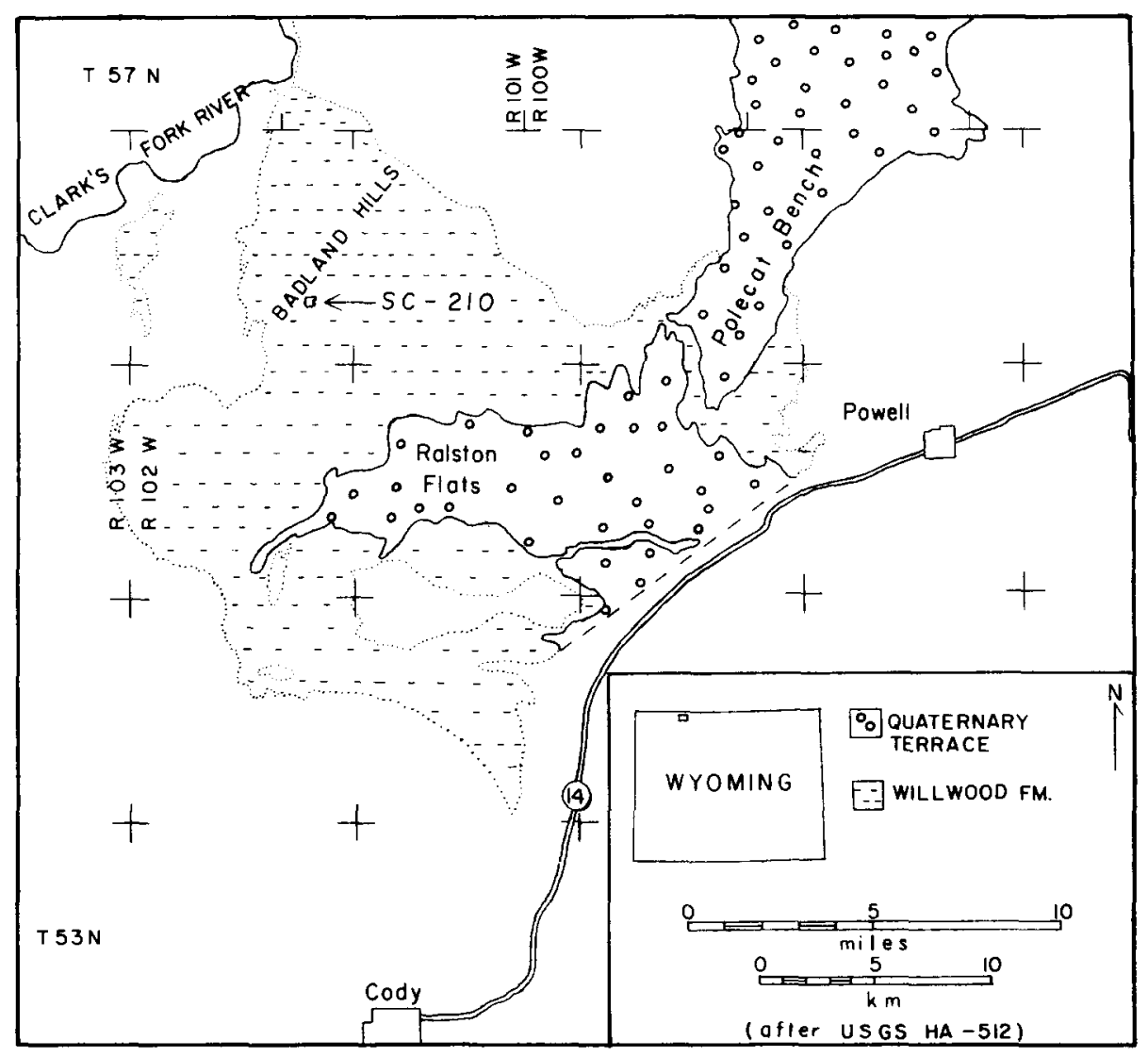

Fig.1. Location map of the study area, locality SC-210, within the Willwood Formation in the Clark's Fork Basin of northwestern Wyoming. 
Field crews from the University of Michigan found, and collected at, more than 200 mammalian localities in the Willwood and Fort Union Formations of the Clark's Fork Basin between 1975 and 1977 (and this work is continuing). The resulting large collections of Paleocene and early Eocene mammals are being studied to determine phylogenies of the taxa and faunal changes through the stratigraphic section (Gingerich, 1976a; Gingerich and Simons, 1977; Gingerich and Gunnell, 1979; Rose, 1981). This is the first study of paleoecology and taphonomy of a representative locality in this extensively sampled area.

\section{METHODS}

In order to conduct this paleoecological analysis it was necessary to select a mammalian locality from which no previous collections had been made, but which was similar in its sedimentology and its stratigraphic and areal outcrop distribution to other localities (Winkler, 1980). A well-defined area of suitable outcrop was found and designated Sand Coulee locality 210 (SC-210; NWt at SC-210 is separated from the neighboring Badland Hills by vegetated flats and drainages.

Six stratigraphic sections were measured and sampled within locality SC210, and these are shown in Fig.3. Measured sections were trenched to find true contacts because the mudstones are weathered to a depth of 6 to $50 \mathrm{~cm}$. Measurements were made with a meter tape and Brunton compass. All occurrences of structures and fossils shown in the sections represent in situ finds in or immediately adjacent to the trenched section. Unit boundaries represent noticeable changes in grain size and/or coloration. No detailed grain size analyses were made. Units labeled as mudstones have little silt-size fraction.

Before any collecting was done, the surface was surveyed with the same intensity given other localities during normal prospecting, and all teeth, jaws, and recognizable postcrania were marked with surveyor's flags. Then a total of $275 \mathrm{~m}$ squares, at three separate stratigraphic levels, were subjected to intense collection by means of a $25 \mathrm{~m}^{2}(5 \mathrm{~m} \times 5 \mathrm{~m})$ quadrat net. All recognizable dental and postcranial specimens were located in each quadrat to the nearest $5 \mathrm{~cm}$. In addition, the locality was subdivided into 65 topographically and stratigraphically defined units (sublocalities) and all fossil remains were collected separately from each sublocality by surface prospecting. Finally, four successive producing horizons in a $10 \mathrm{~m}$ stratigraphic interval were screen washed to sample the fossil content of unweathered sediment. Several areas of in situ fossil concentrations were quarried. The entire area was mapped topographically and geologically using a plane table and alidade. 


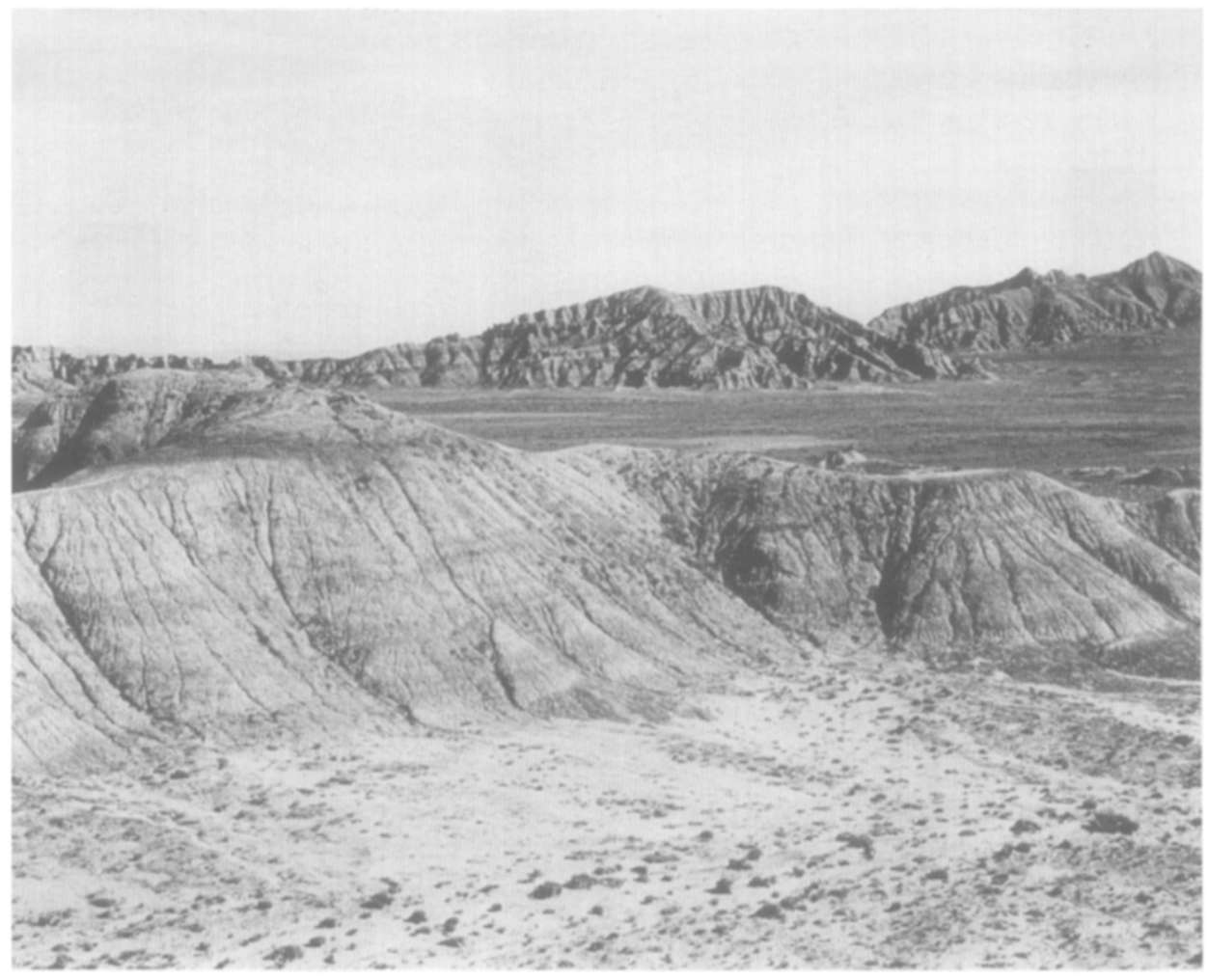

Fig.2. Northern portion of the outcrop at SC-210 facing north. The Badland Hills are visible in the background.

\section{GEOLOGY}

\section{Introduction}

The fluvial sediments of the Willwood Formation are characterized by an alternating series of orange, red, purple and gray mudstones (Van Houten, 1944). In the Sand Coulee area the bright-colored mudstones are commonly orange or red, whereas purple beds are rare. Bedding in the vicinity of the study locality dips uniformly to the southwest, varying from $2^{\circ}$ to $6^{\circ}$.

Locality SC-210 contains approximately $22 \mathrm{~m}$ of section. The beds strike $\mathrm{N} 34^{\circ} \mathrm{W}$ and dip $5^{\circ} \mathrm{SW}$. Tracable mudstone units appear, in outcrop, to be of relatively constant thickness. The differences in thicknesses of similar sequences shown, for instance, between Sections 2 and 4, are largely due to the difficulty of accurately measuring angles on highly variable slopes. 


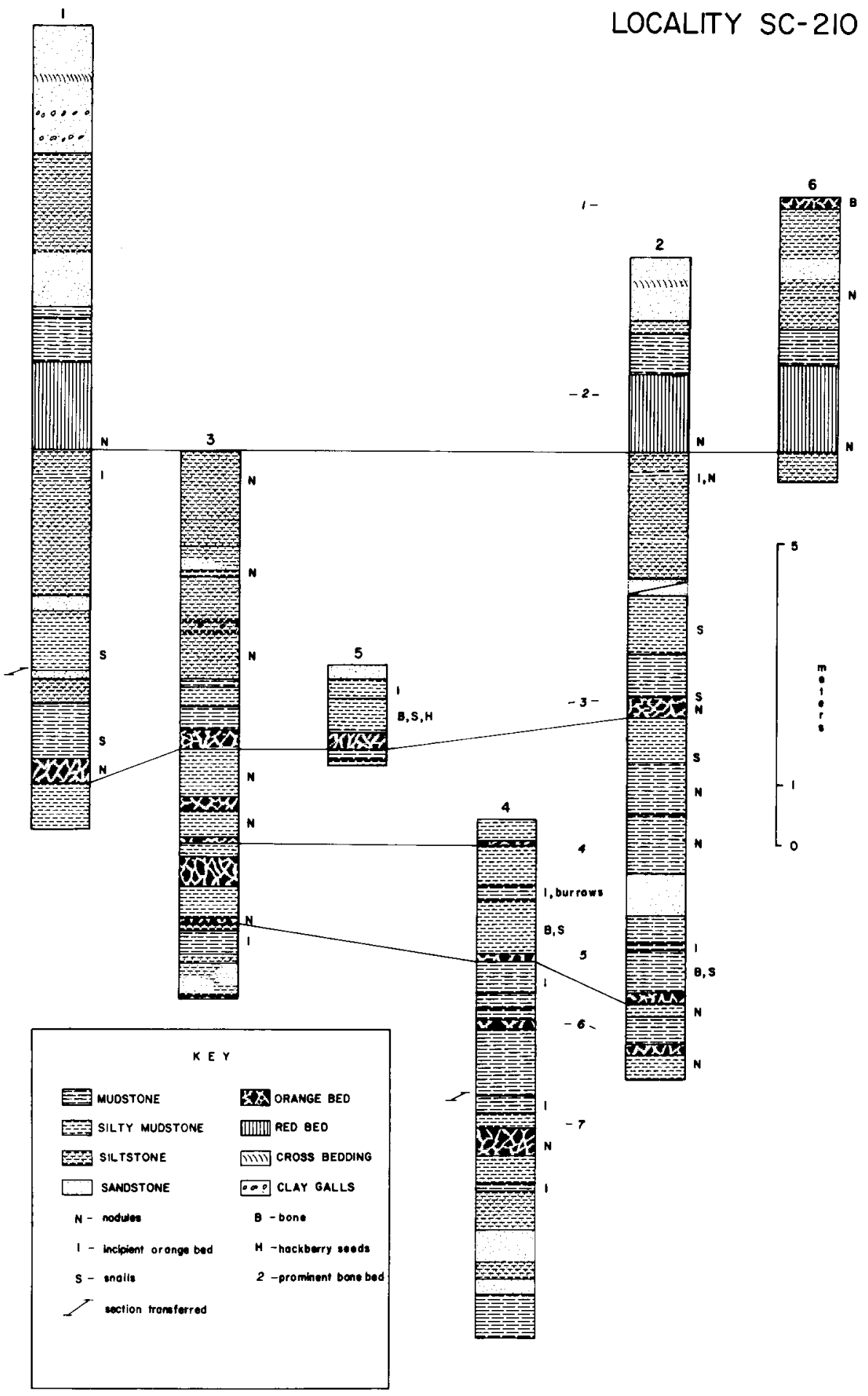

Fig.3. Measured stratigraphic sections in locality SC-210. Position of sections shown in Fig.4. The stratigraphic positions of prominent bone bearing beds are indicated by numbers in italics. Structures and specimens next to the sections represent in situ occurrences. 


\section{Mudstones}

Drab gray or greenish mudstones are volumetrically the most abundant units within SC-210. The locality also contains one red and seven orange mudstones that are visible on weathered outcrop. An additional six mudstone units showed orange mottling in fresh samples but the orange coloration is not visible in weathered outcrop and these beds are labeled incipient orange beds (Fig.3).

The red bed, which is the most conspicuous unit, is overlain by a dark gray mudstone. In fresh samples reddish coloration at the base of the bed intensifies from dispersed mottling in a greenish gray mudstone to more uniform red mud in the middle (Munsell 7.5Y 5/1 to 10R 6/2). In fresh samples the orange beds show orange, red, brown and yellow mottling in a greenish gray matrix (7.5Y 6/2 and 5Y 5/2). Drab mudstones can be divided into two categories based on color. Those that overlie the orange and red beds are always drab colored and, with one exception, all are darker (5Y $4 / 1$ to $5 \mathrm{Y}$ $5 / 1$ ) than other drab mudstones (5Y 6/2 to 7.5Y 6/2). The dark and neutral drab mudstones can also be distinguished on weathered outcrops.

A few mudstones in the locality show shaly lamination, but most are massive. Burrows present in Section 4, as well as abundant wood fragments suggest that bioturbation of sediment was common. Nodules composed of calcium carbonate are the most common structure in the mudstones. Some nodules were up to seven centimeters in long dimension. These are discussed below.

The red and orange colored units are almost always overlain by a dark gray mudstone. The boundaries of red and orange coloration were not found, in any case, to be coincident with the boundaries of recognizable depositional units. In several places an orange bed appeared to vary vertically in grain size (coarsen upward). This may represent development of coloration in several superposed depositional units. In SC-210, the dark gray mudstones which overlie most orange beds are almost always of slightly coarser grain size.

The bright-colored beds are laterally persistent and are of roughly uniform thickness for at least one-half mile from SC-210.

\section{Sandstones and siltstones}

Siltstones within SC-210 are usually drab green (5Y 6/2 to $10 \mathrm{Y} 7 / 2$ ). Most are structureless, but some preserve planar bedding. They grade laterally into both mudstones and sandstones. Contacts between siltstones and mudstones overlying them are often gradational.

The light yellowish brown sandstones in SC-210 are almost entirely of medium grain size $(1.0 \phi)$ or smaller. The majority of sand units are thin tabular bodies which extend throughout much of the locality. In contrast, the sand at the top of Section 1 appears to be a relatively small " $U$ "-shaped channel. Trough crossbedding is clearly visible in two sand units near the top 
of the section in SC-210. The "U"-shaped and tabular sandstones appear to be analogous to Bown's (1979) "apron-channel" and "shoestring" sands, respectively.

\section{Nodules}

Bown (1979) discussed the types of nodules which occur in the Willwood Formation in the southern Bighorn Basin. Nodules occur as surface litter throughout SC-210 and are locally very abundant. Most of the nodules are composed of calcium carbonate (variety 1 of Bown, 1979) and they commonly encrust bone. They were found in situ in both mudstones and siltstones.

The red bed contained one dense zone of nodules roughly $10-20 \mathrm{~cm}$ above the base. Five orange or incipient orange beds were found to contain nodules. These nodules are common where found and probably occur in all orange beds, but their irregular distribution allowed them to be missed in places in the narrow section trenches. Nodules were found to occur in drab as well as brightly-colored mudstones and in siltstones.

\section{Fossils}

Dark gray mudstones are the source of all vertebrate remains and most other types of fossils found in SC-210. These beds, along with their associated brightly-colored mudstones, are labeled as prominent bone beds in Fig.3. There are seven such "couplets" of dark-over-colored mudstones within SC-210 (Braunagel and Stanley, 1977; Bown and Kraus, 1981a, b).

\section{Discussion}

Much controversy exists over the mode of formation of red beds. However, Bown (1979), Bown and Kraus (1981a) and this study concur in suggesting that colored units do not correspond to depositional units (see Braunagel and Stanley, 1977). Based on chemical analysis, Neasham and Vondra (1972) interpret red (and orange) colored units to be B horizons of immature soils formed by post-depositional oxidation of iron minerals. Bown (1979) and Bown and Kraus (1981a) demonstrate more clearly the many analogies of Willwood colored mudstones to soil horizons. The origin of differential mudstone coloration has been shown to be the result of differential hydration or dehydration of brown iron oxides inherited equally by drab and (later) multicolored units (Van Houten, 1968; Bown, 1979; McPherson, 1980). The beds that overlie orange-mottled purple_mudstones (termed "Class A gray mudstones") are always high in organic carbon (Bown, 1979). Bown interprets his Class A gray beds and colored beds to be A and B soil horizons, respectively. Class A gray beds are the source of nearly all fossil vertebrates in the Sand Creek facies of the Willwood Formation and in much of the lower Willwood in the central Bighorn Basin (Bown, 1979). 
Another soil forming process recognized in these sediments is mottling due to gleying in the presence of organic carbon (Bown, 1979; Bown and Kraus, 1981a). This mottling was thought to be caused by bioturbation (Van Houten, 1968, 1973; Braunagel and Stanley, 1977). Gleying occurs during periods when water tables are high and may represent seasons of high rainfall (Mohr and Van Baren, 1954; Bown, 1979; McPherson, 1980). Bown (1979) and Bown and Kraus (1981a) compare the environment of Willwood soil formation to modern warm temperate or subtropical regions typified by seasonally wet and dry periods. Neasham and Vondra (1972) and Bown (1979) agree that fluctuating water tables played an important role in Willwood pedogenesis.

Nodules found within colored mudstones are also analogous to those found in the B horizons of soils (Bown, 1979; Bown and Kraus, 1981a). Nodules present in drab mudstones and siltstones in SC-210 might be explained by stacking of soil profiles and superimposition of their related structures (i.e. nodules; Bown and Kraus, 1981a).

The following points differentiate red beds from orange beds: $(1)$ the red profile in SC-210 is nearly three times as deep as the deepest orange; (2) red coloration within the red bed is similar to some mottled colors of orange beds, but heavy mottling does not occur; (3) nodules occur in the red bed in a very definite layer near the bottom, while their position in orange beds is less clear and they are less dense. Mohr and Van Baren (1954) clearly depict the color development sequence through time of Indonesian soils, which Bown (1979) has compared to Willwood soils, to be from light yellow through orange and brown to red. Based on all the above information, I suggest that the red bed at SC-210 represents a much older and better developed soil profile than orange beds. Therefore, the top of the soil profile with a red B horizon was exposed at the surface for a relatively longer time.

The time required for deposition of the sequence at SC-210 can be estimated indirectly. Gingerich $(1976 \mathrm{~b}, 1980)$ and Rose $(1980,1981)$ have correlated the dated European stratigraphic section in the Paris Basin with North American sequences based on plesiadapid zones. Stratigraphic sections measured within the Sand Coulee Basin span the Paleocene-Eocene boundary and are terminated in the middle of the upper Graybullian subage. Judging from dates published by Berggren et al. (1978), the Eocene part of this section is equivalent to about $3.5 \mathrm{~m} . \mathrm{y}$. Considering the biostratigraphic subdivisions of this 3.5 m.y. period, Gingerich (1980) estimates that one meter of sediment in the Eocene part of the section represents an average of about $3300 \mathrm{yr}$. Thus, the time represented by the section at SC-210 (approximately $22 \mathrm{~m}$ ) is approximately $72,600 \mathrm{yr}$. There are at least fourteen episodes of soil development (red bed, orange beds, or incipient orange beds) in the section at SC-210. Although there is variation in the time required for formation, the average duration of one episode of soil formation appears to have been about $5200 \mathrm{yr}$. This represents a maximum estimate of the duration of soil formation because of erosion throughout the section. 
Bown and Kraus (1981a, p. 23) estimate the average time of paleosol formation in the Willwood to be approximately 6000-9000 yr. Mohr and Van Baren (1954) give an estimate of the rate of tropical soil development in one area as about $15 \mathrm{~cm}$ per $1000 \mathrm{yr}$. and state that profiles of tens of meters require several hundred thousand years to form. While these estimates are only approximate, they do seem to be in general agreement. No paleosols at SC-210 are more than $1.5 \mathrm{~m}$ thick now. Although the original profile must have been thicker before compaction of the mudstones occurred, an estimate of 10,000 yr. for formation of the red bed in the section at SC-210 is reasonable.

Willwood sediments accumulated in a basin characterized by a seasonally wet and dry subtropical to humid tropical climate (Bown, 1979; Bown and Kraus, 1981a). Colored sequences are related to oxidizing conditions (good drainage) and drab sequences to reducing conditions (poor drainage). Paleosols in the Willwood Formation are most like the wet varieties of the spodosol and entisol groups (Bown and Kraus, 1981a). The Willwood flood basin was a largely featureless plain with laterally variable conditions of oxidationreduction relating to local climate, and tectonic and depositional conditions (Bown, 1979; Bown and Kraus, 1981a).

\section{TAPHONOMY AND OCCURRENCE OF FOSSILS}

\section{Introduction}

Collections made by surface prospecting, quadrating, quarrying, and washing, all add taphonomic information crucial to the interpretation of paleoecology. The initial marking of fossils with surveyor's flags allowed visual examination of the spatial distribution of fossils. It became obvious that concentrations of fossils occurred in narrow bands, and that these concentrations were related to dark gray mudstones above orange and red beds. Fossils were also abundant on several areas of outwash flats below areas of exposure of colored beds. Much emphasis in this study is given to analyzing surface collections since this method has been used in the past for nearly all Tertiary mammalian faunas occurring in badlands topography. Any methods that are developed to obtain taphonomic information from such collections could prove very valuable in many future collections.

\section{Quadrats}

Quadrat collections were made to test the association of fossil occurrence on the surface with bedding horizons, and also to estimate actual fossil abundance (see Figs.4 and 5). Fig.5 shows the relationship of jaws and teeth to distance downslope from the gray bed of orange-gray couplet number three in quadrat $\mathrm{AH}$ (the northeastern-most " $\mathrm{A}$ " quadrat). In this fossiliferous quadrat all fossil material was found in high concentration directly on (or 


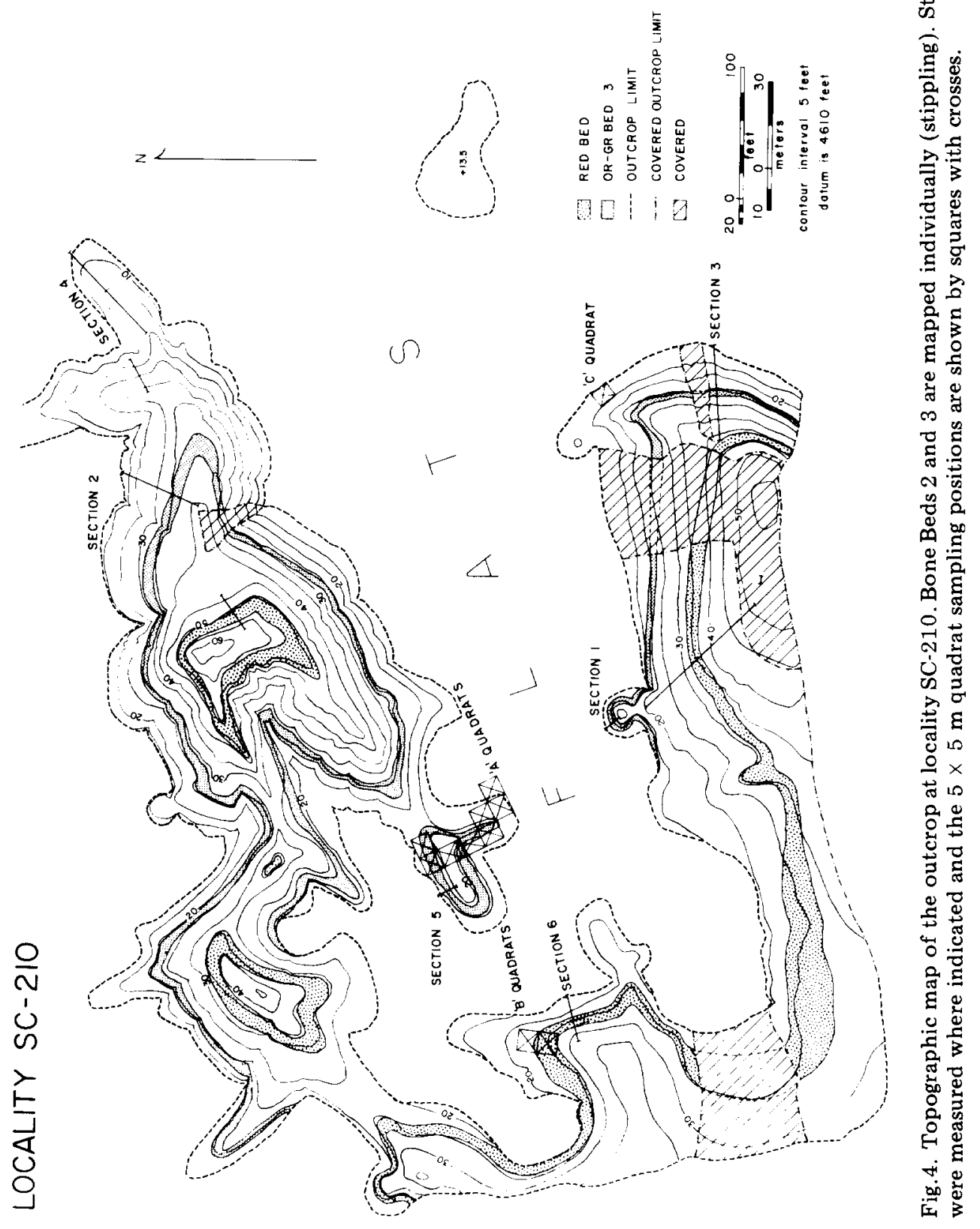


slightly below) the weathered outcrop band of the dark gray bed. The topographically highest quadrat in the " $A$ " series was centered over a flat outcrop of sandstone. Careful examination of the surface revealed only a few small gastropod shell fragments and no other fossil material on this sandstone. The " $B$ " quadrats were laid out on the red bed couplet (number 2), and the " $C$ " quadrat was on Beds 5 and 6. In richer quadrats (e.g. the two northern quadrats in the " $\mathrm{A}$ " series) the concentration of fossil material dropped sharply downslope away from the source bed (dark gray bed). This presumably is related to destruction and reburial of fossil material on the surface.

Flagged specimens unexpectedly provided a means to measure downslope fossil movement after two or three rainstorms in the summer. Movement of specimens within quadrats ranged from 0 to $50 \mathrm{~cm}$, with much less movement in areas with heavy nodule cover. These facts, along with the rapid drop in fossil concentration away from gray beds, suggest relatively rapid turnover of specimens on the outcrop surface. Bown and Kraus (1981b) estimate the average surface exposure time of specimens in the central Bighorn Basin to be about three to six years and possibly much longer in areas with heavy nodule cover. This estimate seems reasonable, or possibly even somewhat high for the Sand Coulee area.

Surface abundances of different fossil material varies greatly. Table I shows the relative abundance of fossil items expressed as a percentage of the number of square meters that contained them in each of the quadrat areas. In general, fossils are less abundant in the " $B$ " quadrats than the " $A$ " or " $C$ " quadrats. Snails and Celtis seeds are especially rare in the "B" quadrats, and in general on the red bed. The occurrence of mammalian dental and skeletal elements is relatively uniform in all areas. No fossilized wood was found on

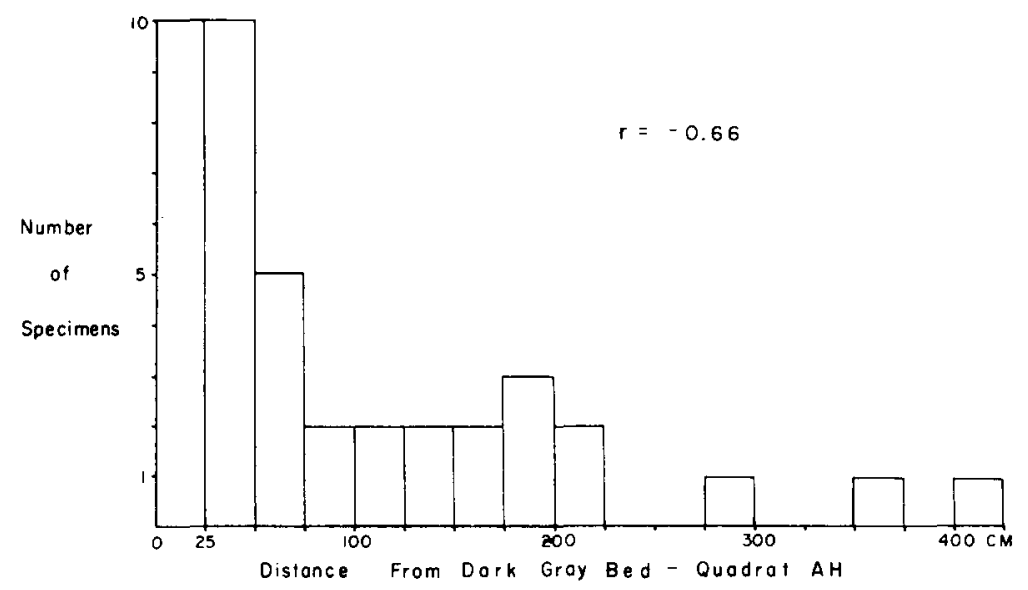

Fig.5. Histogram of the number of dental and postcranial specimens of fossil vertebrates found while collecting the surface of quadrat $\mathrm{AH}$ as a function of their distance downslope from Bone Bed 3. The correlation coefficient $(r)$ for the number of specimens versus distance is -0.66 . Rapid destruction and reburial of exhumed fossil material is indicated. 
TABLE I

Fossil abundance in SC-210 expressed as the percentage of surface quadrats containing given items

\begin{tabular}{llccc}
\hline Item & $\begin{array}{l}\text { A quadrats } \\
(N=200)\end{array}$ & $\begin{array}{l}\text { B quadrats } \\
(N=50)\end{array}$ & $\begin{array}{l}\text { C quadrats } \\
(N=25)\end{array}$ & $\begin{array}{l}\text { All } \\
(N=275)\end{array}$ \\
\hline Bone fragments & 58.0 & 56.0 & 100.0 & 61.4 \\
Snail fragments & 63.0 & 14.0 & 68.0 & 54.5 \\
Hackberry seeds & 47.0 & 10.0 & 40.0 & 41.4 \\
Snails (whole) & 43.0 & 8.0 & 8.0 & 33.4 \\
Lizard scutes & 26.5 & 20.0 & 40.0 & 26.5 \\
Mammalian taxa & 25.0 & 14.0 & 36.0 & 24.0 \\
Isolated teeth & 21.5 & 18.0 & 24.0 & 21.1 \\
Postcrania & 19.0 & 2.0 & 28.0 & 16.7 \\
Wood fragments & 18.5 & 0.0 & 0.0 & 13.4 \\
Diaphyses & 11.5 & 6.0 & 4.0 & 9.8 \\
Dentaries & 10.5 & 0.0 & 16.0 & 9.1 \\
Maxillae & 6.5 & 0.0 & 0.0 & 4.7 \\
White bone & 0.0 & 12.0 & 0.0 & 2.2 \\
\hline
\end{tabular}

the " $B$ " quadrats. White bone, restricted to the " $B$ " quadrats, is bone that appears to be thoroughly bleached. Bone is normally dull to moderately shiny black. Some teeth found on the red bed couplet (off the "B" quadrats) are also bleached. This all points to differences between red and orange beds, including possible chemical differences.

Another estimate of abundance is the average number of items per square meter in each fossil category (Table II). This estimate shows even more clearly the preservational differences in elements, such as between dentaries and maxillae. The differences between the red bed (" $B$ " quadrats) and orange beds (" $A$ "-" $C$ " quadrats) are also more striking. The number of snail fragments is a ranked variable (e.g. abundant, rare) and is not included. Volume is the best estimate of fossil abundance but could not readily be measured on thousands of separate specimens.

\section{Wash and quarry collections}

The association of fossils with dark gray beds of colored-and-gray couplets indicated by flagging and quadrating is substantiated by quarry and wash samples. Bone and teeth were found in situ in several areas while sampling stratigraphic sections (see Fig.3). In addition, the fossiliferous layers near the top of the northwestern-most of the "A" quadrats (Bed 3) and Bed 5, near Section 4 , were carefully quarried. Bone, teeth, hackberry seeds and snails were all found dispersed through only 15 to $20 \mathrm{~cm}$ of the dark silty mudstone.

Screen washing of fresh sediment was done to: (1) estimate fossil volume; (2) confirm the fossil content in random samples of several bone beds; (3) provide an estimate of the true relative abundances of the fauna (especially 


\section{TABLE II}

Fossil abundance in SC-210 expressed as the average number of items per square meter in quadrats

\begin{tabular}{lllll}
\hline Item & $\begin{array}{l}\text { A quadrats } \\
\left(200 \mathrm{~m}^{2}\right)\end{array}$ & $\begin{array}{l}\text { B quadrats } \\
\left(50 \mathrm{~m}^{2}\right)\end{array}$ & $\begin{array}{l}\text { C quadrats } \\
\left(25 \mathrm{~m}^{2}\right)\end{array}$ & $\begin{array}{l}\text { All } \\
\left(275 \mathrm{~m}^{2}\right)\end{array}$ \\
\hline Bone fragments & 4.56 & 1.42 & 5.92 & 4.11 \\
Hackberry seeds & 3.14 & 0.44 & 0.72 & 2.42 \\
Snails (whole) & 1.08 & 0.10 & 0.08 & 0.81 \\
Lizard scutes & 0.60 & 0.28 & 1.04 & 0.58 \\
Postcrania & 0.46 & 0.02 & 0.32 & 0.36 \\
Isolated teeth & 0.34 & 0.24 & 0.40 & 0.33 \\
Wood fragments & 0.36 & 0.00 & 0.00 & 0.26 \\
Diaphyses & 0.30 & 0.06 & 0.04 & 0.23 \\
Dentaries & 0.25 & 0.00 & 0.16 & 0.20 \\
Maxillae & 0.08 & 0.00 & 0.00 & 0.05 \\
White bone & 0.00 & 0.12 & 0.00 & 0.02 \\
\hline
\end{tabular}

the very small forms); and (4) test differences in the types of fossils preserved in different bone beds. Sediment samples were soaked over night and washed through fine screen using a gentle spray of water. Forty gallons (151.4 1) of dry matrix from four sites were washed -25 gal. (94.7 l) from Wash Site 1, 10 gal. (37.8 1) from Wash Site 2, and 5 gal. (18.9 l) each from Wash Sites 3 and 4 . All washing samples contained fossil bone. Wash Site 4 was found to be contaminated by surface debris, so less than 5 gal. (18.9 1) of fresh matrix was actually washed. The bone beds from which wash samples were taken are Bed 2 (Wash Site 3), Bed 3 (Wash Site 1), Bed 5 (Wash Site 2), and Bed 6 (Wash Site 4). Compositional differences will be discussed below.

All fragments of fossil material were removed from the concentrate of Wash Site 1 under a binocular microscope. Measurement of loose volume (as was done for the original matrix) for various fossil types is shown in Table III. Mammalian skeletal remains are by far most abundant. The estimate for the volume of snail material is low since the snail shells in fresh matrix break up during washing and do not represent the volume of the whole animal. Wood fragments are few in number but large in volume. Although Wash Site 1 is very fossiliferous, fresh matrix from this site contains less than one tenth of one percent of fossil material.

\section{Surface collections}

The 65 sublocalities are shown in Fig.6. They were chosen to maximize the number of areas that isolated a particular fossiliferous layer from mixing with others. Outcrop faces were subdivided vertically by prominent, easily traceable beds, such as brightly-colored beds or thin sandstones. Sublocalities that isolate a particular bed are those on tops of hills or small mounds and flats that could receive no wash from above. Table IV shows the bone beds present in each sublocality. 
TABLE III

Volume of fossil material from Wash Site 1

\begin{tabular}{lrcrc}
\hline Item & $\begin{array}{l}\text { Cubic } \\
\text { inches }\end{array}$ & $\begin{array}{l}\text { Cubic } \\
\text { centimeters }\end{array}$ & $\begin{array}{l}\text { Percent } \\
\text { of fossils }\end{array}$ & $\begin{array}{l}\text { Percent of } \\
\text { total matrix }\end{array}$ \\
\hline $\begin{array}{l}\text { Bone - Postcrania and } \\
\text { indeterminate }\end{array}$ & 2.55 & 41.85 & 47.07 & 0.0440 \\
Snails & 1.40 & 22.95 & 25.82 & 0.0240 \\
Wood & 0.69 & 11.34 & 12.76 & 0.0120 \\
Hackberry seeds & 0.45 & 7.45 & 8.38 & 0.0079 \\
Lizard scutes & 0.21 & 3.51 & 3.95 & 0.0037 \\
Teeth and jaws & $\underline{0.11}$ & $\underline{1.80}$ & $-\underline{2.02}$ & $\underline{0.0019}$ \\
Total - Fossil & $\mathbf{5 . 4 1}$ & 88.90 & 100.00 & 0.0940 \\
Total matrix & 5775.00 & 94635.30 & - & 100 \\
\hline
\end{tabular}

Surface collection of isolated beds also confirms that Bone Beds $1-3$ and 5-7 do contain fossil material. Sublocality YS2 isolates Bed 4; however, because only one mammal tooth and little else was found here, the evidence is not conclusive that this bed contains vertebrate materials. Incipient orange beds and their overlying drab beds may also be a source of fossils, but due to their close spacing in outcrop, the evidence is equivocal. If fossils are associated with these beds, they are not abundant.

The relative abundance of fossil elements expressed as a percentage of their occurrence in sublocalities is shown in Table V. Fossil abundance varied between, and laterally within, bone beds. Table $\mathrm{V}$ shows that mammalian remains are by far the most common fossils preserved. The least represented groups are aquatic snails, white bone fragments, and wood. The estimates of abundance in sublocalities are less precise than in quadrat samples since sublocalities were not collected as intensively, but the estimates should accurately reflect variation within the whole locality.

\section{Fossil preservation}

The condition of fossil material provides evidence of the processes operating before burial. All bone in SC-210 is extremely fragmented. Almost no complete postcranial elements were preserved. This is, in part, due to presentday erosion and destruction, but quarrying and washing showed that much fragmentation had occurred before burial. No bone showed signs of current abrasion. In several cases teeth appeared to lack enamel, but this is most likely due to leaching, or ingestion by carnivorous animals (probably crocodilians; Fisher, 1981). Several wood fragments found in sublocality XB are somewhat rounded and may be waterworn. Bone fragments found in situ are isolated in matrix from others and show sharply broken edges. Some bone fragments found in place are very delicate splinters. No appreciable hydraulic transport 

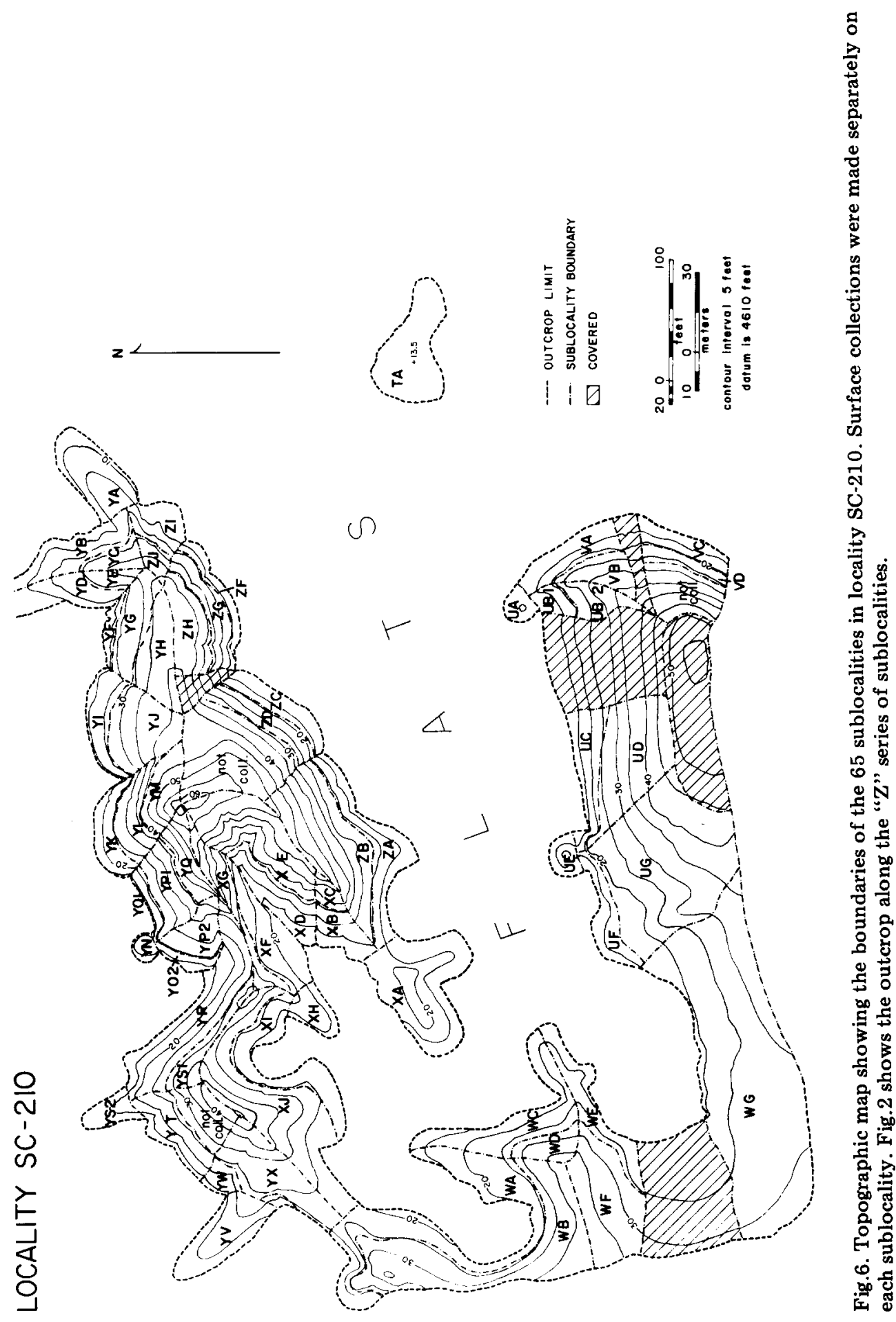
TABLE IV

Distribution of bone beds in sublocalities - sublocalities in geographic sequence (see Fig.6)

\begin{tabular}{|c|c|c|c|c|c|c|c|c|c|c|c|c|c|c|c|c|c|c|c|c|c|c|}
\hline \multirow{2}{*}{$\begin{array}{l}\text { Sub- } \\
\text { locality }\end{array}$} & \multicolumn{7}{|c|}{ Bone Bed } & \multirow{2}{*}{$\begin{array}{l}\text { Sub- } \\
\text { locality }\end{array}$} & \multicolumn{7}{|c|}{ Bone Bed } & \multirow{2}{*}{$\begin{array}{l}\text { Sub- } \\
\text { locality }\end{array}$} & \multicolumn{6}{|c|}{ Bone Bed } \\
\hline & 1 & 2 & 3 & 4 & 5 & 6 & 7 & & 1 & 2 & 3 & 4 & 5 & 6 & 7 & & 1 & 2 & 3 & 4 & 5 & 67 \\
\hline TA & & & & & & & $x$ & $\mathrm{YC}$ & & & & & $x$ & & & YX & & $x$ & & & & \\
\hline $\mathrm{XA}$ & & & $x$ & & & & & YD & & & & & & $x$ & $x$ & YV & & & $x$ & & & \\
\hline XB & & & $x$ & & & & & YE & & & & & $x$ & & & WA & & $x$ & & & & \\
\hline $\mathrm{XC}$ & & $?$ & & & & & & YF & & & & & & $x$ & & WB & $x$ & & & & & \\
\hline XD & & & $x$ & & & & & YG & & & & $x$ & $x$ & & & WC & & $x$ & & & & \\
\hline $\mathrm{XE}$ & & $x$ & & & & & & YH & & & $x$ & & & & & WD & $x$ & & & & & \\
\hline $\mathrm{XF}$ & & & $x$ & & & & & YI & & & & & $x$ & $x$ & & WE & & $x$ & & & & \\
\hline$X G$ & & $x$ & & & & & & Y J & & & $x$ & & & & & WF & $x$ & & & & & \\
\hline $\mathrm{XH}$ & & & $x$ & & & & & YK & & & & & $x$ & $x$ & & WG & & $x$ & & & & \\
\hline XI & & & $x$ & & & & & YL & & & $x$ & $x$ & & & & UA & & & & & $x$ & \\
\hline $\mathrm{XJ}$ & & $x$ & & & & & & YM & & $x$ & & & & & & UB1 & & & & $x$ & & \\
\hline $\mathrm{ZA}$ & & & & $x$ & & & & YN & & & & & $x$ & & & UB2 & & $x$ & $x$ & & & \\
\hline $\mathrm{ZB}$ & & & $x$ & & & & & YO1 & & & & & $x$ & & & $\mathrm{UC}$ & & & $x$ & & & \\
\hline $\mathrm{ZC}$ & & & & $x$ & $x$ & & & YP1 & & & $x$ & $x$ & & & & UD & & $x$ & & & & \\
\hline ZD & & & $x$ & $x$ & & & & YQ & & $x$ & & & & & & UE & & & $x$ & & & \\
\hline $\mathrm{ZF}$ & & & & & & & $x$ & YO2 & & & & $x$ & $x$ & & & UF & & & $x$ & & & \\
\hline ZG & & & & & $x$ & $x$ & & YP2 & & & $x$ & & & & & UG & & $x$ & & & & \\
\hline $\mathrm{ZH}$ & & & $x$ & $x$ & & & & YR & & & & $x$ & $x$ & & & VA & & & & $x$ & $x$ & $x$ \\
\hline ZI & & & & & & $x$ & $x$ & YS1 & & $x$ & $x$ & & & & & VB & & & $x$ & & & \\
\hline ZJ & & & & & $x$ & & & YS2 & & & & $x$ & & & & VC & & & & $x$ & $x$ & $x$ \\
\hline YA & & & & & & & $x$ & YT & & & $x$ & $x$ & & & & VD & & & $x$ & & & \\
\hline YB & & & & & & $x$ & $x$ & YW & & & $x$ & & & & & & & & & & & \\
\hline
\end{tabular}

TABLE V

Relative abundance of fossil material in SC-210 expressed as the percentage of sublocalities containing given items

\begin{tabular}{|c|c|c|c|}
\hline Item & $\begin{array}{l}\% \text { of } \\
\text { sublocalities }\end{array}$ & Item & $\begin{array}{l}\% \text { of } \\
\text { sublocalities }\end{array}$ \\
\hline Bone fragments & 96.9 & Hackberry seeds & 49.2 \\
\hline Mammalian taxa (identifiable remains) & 90.8 & Dentaries (edentulous) & 46.2 \\
\hline Isolated teeth & 81.5 & Maxillae (gnathos) & 43.1 \\
\hline Lizard scutes & 76.9 & Diaphyses & 40.0 \\
\hline Postcrania & 67.7 & Wood fragments & 30.7 \\
\hline Dentaries (gnathos) & 67.7 & Snails (aquatic) & 23.1 \\
\hline Snails (present) & 66.1 & White bone & 23.1 \\
\hline Snails (whole) & 60.0 & Maxillae (edentulous) & 6.2 \\
\hline Snails (terrestrial) & 52.3 & & \\
\hline
\end{tabular}

of these remains could have occurred. The majority of fossil remains must represent surface accumulations that were moved tens of centimeters or a few meters, if at all, before burial.

Voorhies (1969) and Behrensmeyer (1975) have shown that the types and abundances of skeletal elements preserved give a good indication of whether 
sorting and transportation of the remains have occurred. Lighter elements tend to be transported away from a carcass while denser elements remain as lag deposits. Table VI compares the numbers and relative percentages of various skeletal elements in surface and wash collections. Fragments of elements were counted in each category as one specimen. Dentaries and maxillae usually contain only two or three teeth. Since most isolated tooth fragments are identifiable to species, each fragment was counted as one specimen. Dental remains are by far the most common elements preserved. Some bias is shown in the surface collections and this is probably due to the fact that collectors are trained to look specifically for teeth. Most skeletal elements

\section{TABLE VI}

Relative abundance of mammalian skeletal elements in the surface and wash collections in SC-210

\begin{tabular}{|c|c|c|c|c|}
\hline \multirow[t]{2}{*}{ Element } & \multicolumn{2}{|c|}{ Surface collection } & \multicolumn{2}{|c|}{ Wash sites } \\
\hline & No. & $\%$ & No. & $\%$ \\
\hline Isolated teeth & 452 & 34.7 & 93 & 21.4 \\
\hline Dentaries & 389 & 29.9 & 37 & 8.5 \\
\hline Diaphyses & 129 & 9.9 & 113 & 26.0 \\
\hline Maxillae & 66 & 5.1 & 4 & 0.9 \\
\hline Phalanges (whole) & 25 & 1.9 & 12 & 2.8 \\
\hline proximal & 14 & 1.1 & 25 & 5.7 \\
\hline distal & 12 & 0.9 & 13 & 3.0 \\
\hline ungual & 7 & 0.5 & 7 & 1.6 \\
\hline Vertebrae (whole) & 20 & 1.5 & 1 & 0.2 \\
\hline arch fragments & 7 & 0.5 & 18 & 3.3 \\
\hline centra & 10 & 0.8 & 6 & 1.4 \\
\hline caudal & 17 & 1.3 & 24 & 5.5 \\
\hline Pelvis fragments & 19 & 1.5 & 0 & 0.0 \\
\hline Femora - proximal & 18 & 1.4 & 3 & 0.7 \\
\hline - distal & 8 & 0.6 & 1 & 0.2 \\
\hline Calcanei & 15 & 1.2 & 1 & 0.2 \\
\hline Metapodia - proximal & 5 & 0.4 & 7 & 1.6 \\
\hline - distal & 14 & 1.1 & 17 & 3.9 \\
\hline Astragali & 13 & 1.0 & 3 & 0.7 \\
\hline Tibiae - proximal & 4 & 0.3 & 1 & 0.2 \\
\hline - distal & 12 & 0.9 & 4 & 0.9 \\
\hline Humeri - proximal & 8 & 0.6 & 5 & 1.1 \\
\hline - distal & 7 & 0.5 & 12 & 2.8 \\
\hline Ulnae - proximal & 6 & 0.5 & 2 & 0.5 \\
\hline Palates & 5 & 0.4 & 1 & 0.2 \\
\hline Radii - proximal & 3 & 0.2 & 2 & 0.5 \\
\hline - distal & 1 & 0.1 & 0 & 0.0 \\
\hline Occipital condyles & 3 & 0.2 & 1 & 0.2 \\
\hline Podials & 3 & 0.2 & 3 & 0.7 \\
\hline Fibulae - proximal & 2 & 0.2 & 1 & 0.2 \\
\hline Ribs & 0 & 0.0 & 10 & 2.3 \\
\hline Patellae & 0 & 0.0 & 2 & 0.5 \\
\hline Total & 1302 & 100.0 & 435 & 99.9 \\
\hline
\end{tabular}


are present in small numbers and no strong preservational bias is shown. Next to dental remains, vertebrae, metapodials and phalanges are the most common elements.

Voorhies (1969) grouped skeletal elements into three categories based on transportability. The elements preserved at SC-210 show no bias due to transport. The most commonly preserved elements are at opposite ends of the transport spectrum. Vertebrae and phalanges are common and are easily transported while teeth, which are moved last by currents, are also very abundant. Voorhies worked mainly with bones of larger mammals, but Dodson (1973) found similar results for small mammalian skeletons. The first elements of a mouse skeleton to be moved by currents were the vertebrae and the last were the incisors (Dodson, 1973). Skeletal preservation further documents the lack of sorting or transportation of the assemblage at SC-210. Changes in the relative abundance of elements from original ratios must be due to differences in the resistance to weathering or destruction of some elements after death of the animal. Carnivore activity may play a role in skeletal destruction. As expected, teeth are most resistant to weathering and breakage, which accounts for their being more common than other elements. Other elements that are relatively abundant are dense or small and compact elements such as phalanges and caudal vertebrae. Some more delicate elements, such as vertebral arch fragments, are common because even tiny pieces are identifiable. This is not the case with larger elements which are not so uniquely constructed. There is probably some general bias in the tallies due to the ease or difficulty of identifying various elements. For instance, nearly all the pelvis fragments identified in the surface collection preserve the acetabulum. Flat portions of the pelvis would be difficult to identify with certainty.

Elements from the washed samples are highly fragmented and somewhat altered in relative proportion due to the washing process itself. Bone in fresh matrix is wet and highly fragile, and some breakage undoubtedly occurs during washing. This may account for the high proportion of isolated teeth, rather than dentaries or maxillae containing teeth, in washing concentrates. Any washed concentrate contains a very large number of unidentifiable bone fragments. Surface collections contain more complete elements because slow drying and hardening of the bone occurs as it weathers out.

Washed samples probably give a more representative estimate of original skeletal composition. The main differences from surface collections are the lower numbers of dental versus postcranial elements in the wash. This may be due, in part, to selective destruction of elements, and as mentioned, it may also be due to collector bias.

The fossil assemblage at SC-210 represents the fragmented remains of skeletons that accumulated on soil surfaces. Little or no current transport of bone occurred, and postmortem weathering and carnivore activity acted to produce this assemblage. 
TABLE VII

Faunal list of SC-210

\section{GASTROPODA}

Order Ctenobranchiata

Family Viviparidae

Viviparus sp.

Order Basommatophora

Family Physidae Physa sp.

Order Stylommatophora

Suborder Sigmurethra

Family Endodontidae Discus sp.

Family Oreohelicidae Oreohelix sp.

Family Polygyridae Polygyra sp.

Family Zontidae Gastrodonta sp.

Family Grangerellidae Grangerella sp. Protoboysia complicata

Family Pupillidae

Genus indet. $-t$ wo species

Family Indet. - three or more terrestrial types

\section{OSTEICHTHYES}

Order Semionotiformes

Suborder Lepisostoidei

Family Lepisosteidae Lepisosteus sp.

Order Amiiformes

Suborder Amioidei

Family Amiidae Amia sp.

\section{AMPHIBIA}

Order Anura

Family indet.

\section{REPTILIA}

Order Crocodilia

Suborder Eusuchia

Family Alligatoridae

Allognathusuchus sp.

Order Squamata

Family Anguidae

Subfamily Anguinae

Odaxosaurus cf. jepseni

cf. Gerrhonotus sp. 
TABLE VII (continued)

Subfamily Glyptosaurinae

Paraglyptosaurus sp.

Melanosaurus maximus

Order Testudines

Suborder Cryptodira

Family Baenidae

"Baena"sp.

AVES

Indet. - egg shell fragments

MAMMALIA

Order Multituberculata

Family Neoplagiolacidae

Ectypodus tardus

Order "Insectivora"

Family Palaeoryctidae cf. Palaeoryctes sp.

Family Leptictidae cf. Prodiacodon sp.

Family Dormaalidae cf. Talpavus sp.

Family Erinaceidae cf. Leipsanolestes sp.

Genus and species indet.

Family indet.

Order Primates

Family Microsyopidae Microsyops wilsoni

Family Paromomyidae Phenacolemur praecox

Family Adapidae Pelycodus ralstoni

Family Omomyidae Tetonoides tenuiculus

Order Tillodontia

Family Esthonychidae Esthonyx spatularius

Order Taeniodonta

Family Stylinodontidae Ectoganus sp.

Order Rodentia

Family Ischyromyidae cf. Paramys - three spp.

Order Creodonta

Family Oxyaenidae Oxyaena gulo

Family Hyaenodontidae Arfia sp. Tritemnodon sp. Prototomus sp. 
TABLE VII (continued)

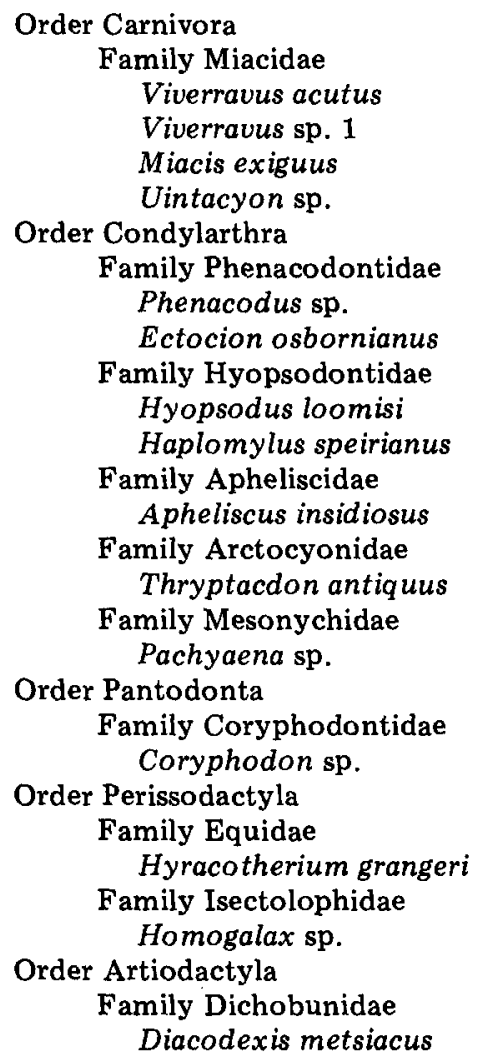

FAUNAL ANALYSIS

\section{Taxonomy}

Table VII shows all mammalian and non-mammalian taxa found at SC-210. Gastropods were identified from the literature and from a small reference collection provided by Dr. J. Hanley. Several morphotypes of terrestrial gastropods are undescribed and are not listed.

All Reptilia were identified by W. S. Bartels. D. W. Krause identified the multituberculate, and $\mathrm{H}$. Deutsch identified the hyaenodontid creodonts. All other identifications were made by the author using comparative collections and casts at the University of Michigan. Many taxonomic groups are currently being revised and consequently several of the taxa listed are undescribed species.

The ischyromyids are sorted into three species based on clusters of incisor sizes (A being the largest). They may not all belong to the genus Paramys, but inadequate material prohibited further identification. Identifications of 
the Insectivora (including Proteutheria) are very tentative and await further study of these complex orders.

Additional screen washing done in the summers of 1979 and 1980 at Wash Site 1 produced the first specimens of Microsyops wilsoni and anurans. These taxa were added to the faunal list, but are not included in the quantitative analysis.

\section{Biotic associations}

Three sets of data were compiled and used to test biotic and lithological associations within SC-210. All statistical analysis was done using the University of Michigan Statistical Research Laboratories' MIDAS programs. The first data set is a count of the abundance of fossils within each square meter of quadrat samples. Variables used are those in Tables I and II. The one square meter quadrats were entered as cases. Correlation coefficients on these data provide a measure of the spatial association of types of fossils on a very small scale based upon their abundance. A strong relationship is shown between all categories of mammalian remains, wood fragments and hackberries (0.520.78 ). In contrast, these categories were not strongly correlated with whole snails $(0.31-0.51)$. This presumably indicates that terrestrial gastropods require a different set of micro-conditions for fossilization than other fossil materials. This probably relates to their calcium carbonate skeleton.

Analysis was performed on a second set of data consisting of counts of fossil items (variables) within all sublocalities (cases). These data do not include counts from quadrat collections because this would strongly bias counts of many categories for those sublocalities containing quadrats.

It is important to know if fossil abundance and diversity varies either laterally (geographically) or stratigraphically (temporally). Systematic patterns of fossil occurrence have been used as a basis for interpretation of paleoecology (Behrensmeyer, 1975; Behrensmeyer et al., 1979), and this approach is also possible with early Eocene animals. To test for possible patterns of fossil occurrence and the source of such patterns, a principle component analysis was performed on the abundance of fossil types in each sublocality. The 31 variables used are an elaboration of those in Table $\mathrm{V}$ with the addition of the occurrence of bone beds in sublocalities. This type of analysis calculates linear combinations of values for variables to make new variables. This first principle component is calculated from the variable-by-variable correlation matrix. It is this axis that contains the maximum variation. The next axis is computed to be orthogonal, or uncorrelated, with the first axis and explains less of the variation in the data. Fig. 7 shows a scatter plot of the scores of the 65 sublocalities on principle components I and II.

The variance in this data set is not easily condensed for explanation by a few components. Fifteen principle component axes were necessary to explain $90 \%$ of the variance and many of these represent mainly single variables. The pattern in Fig.7, and in other combinations of principle component axes, is 


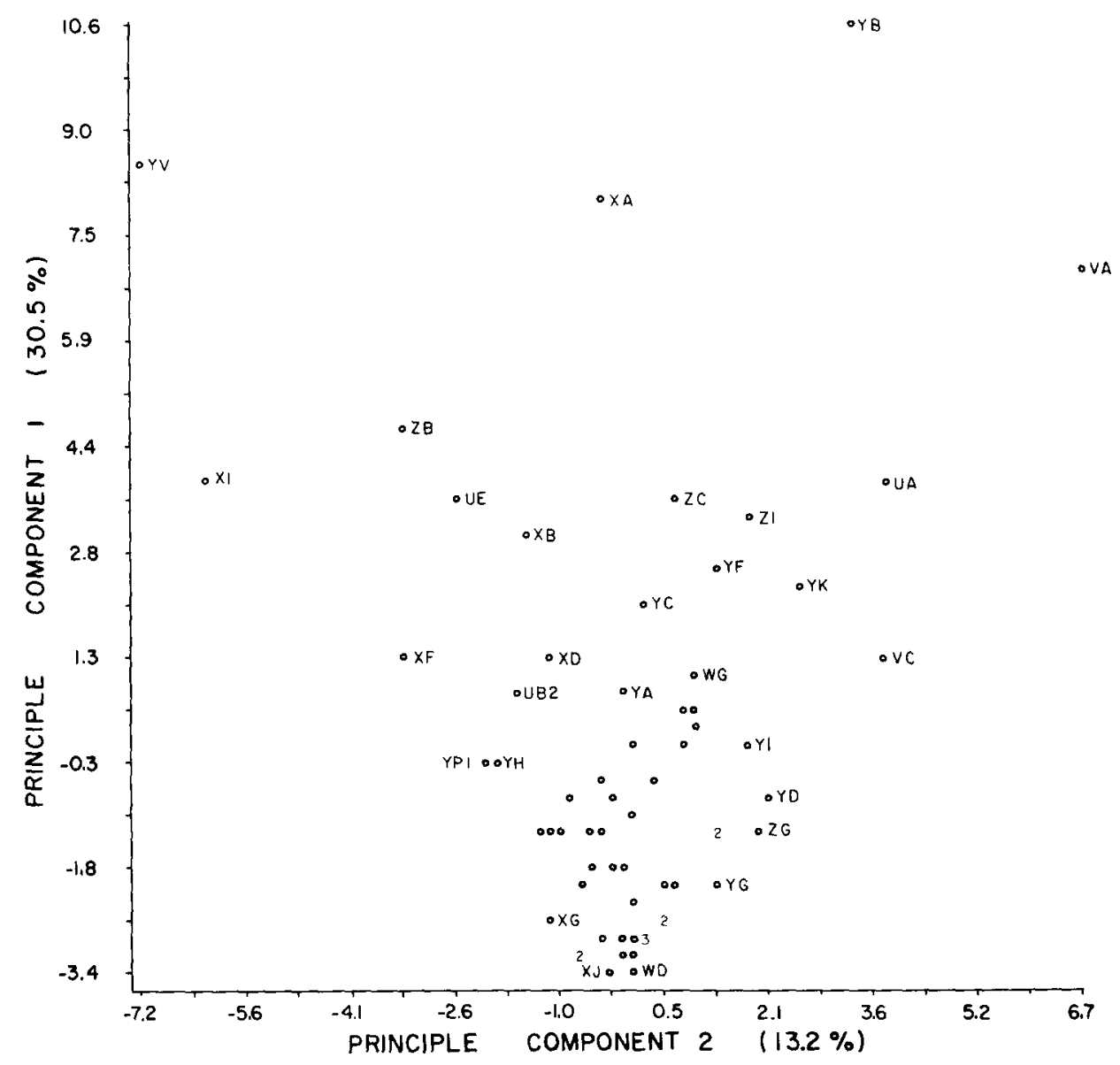

Fig.7. Scatter diagram of the scores of the sublocalities (cases) on the first and second principle component axes. Thirty-one variables are used to compare the sublocalities. The scores are a measurement of the relationship of the sublocality to the variables that make up each axis. The more distinct sublocalities are labeled. The percentage of the total variation explained by each axis is given.

one of heterogeneity between sublocalities, with no clear groupings because there are no strong correlations between any of the variables on this scale. A few sublocalities are strikingly different from the others. There are, however, certain patterns which emerge among the variables. Loading on principle component I (or correlations with this axis) show that this axis represents mainly the positive correlation between the abundant occurrence of most types of fossil material (see Fig.8). Values of positive correlation range from 0.27 for isolated bone fragments and mammalian dentaries to near zero for wood, Bed 5 and Bed 7. Negative loadings of variables on principle component I are weak or insignificant but are shown by Bed $2(-0.11)$, Bed 1 $(-0.05)$, white bone $(-0.05)$, Bed $4(-0.03)$, and wood $(-0.09)$. The presence 


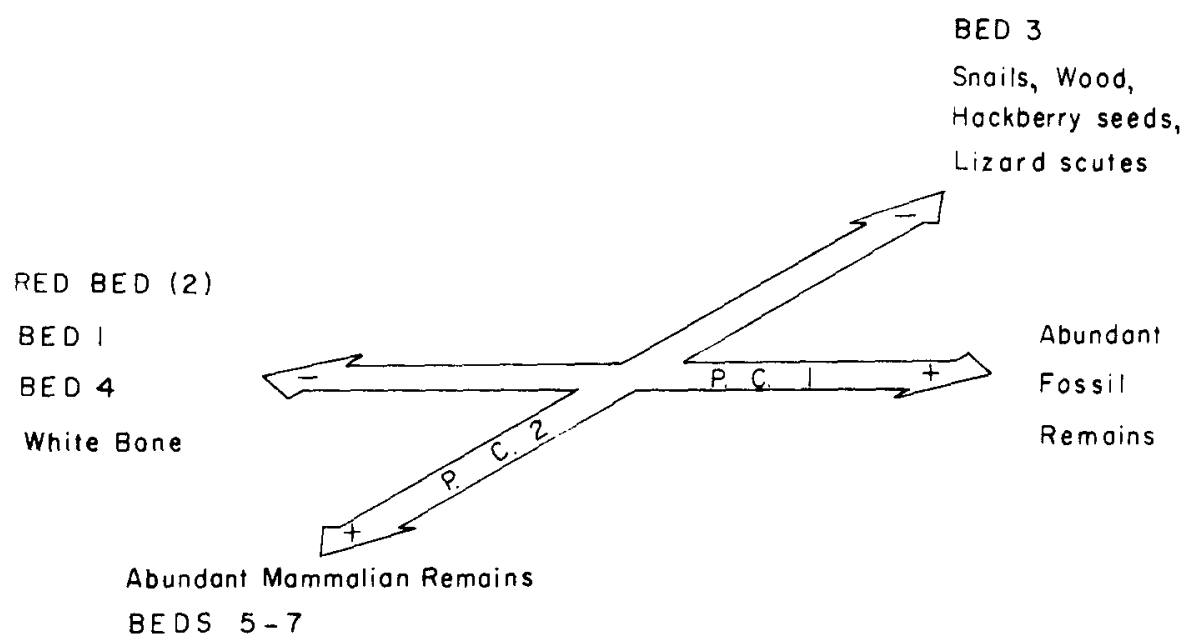

Fig.8. Oblique view of the first two principal axes of Fig.7 showing an interpretation of the observed correlations (loadings) of variables. The variation in principal component $I$ is largely due to the abundance of all types of fossil remains, while principal component II expresses the variation in the abundance of mammalian fossils.

of Beds 5 and 6 are positively correlated with principle component II $(0.24$ and 0.30 , respectively). Mammalian skeletal categories, the number of taxa (0.19), and Bed 7 (0.11) are also positively correlated with this axis. Negative loadings on principle component II are shown by snails $(-0.33$ for one category of snails) and especially aquatic snails, hackberry seeds $(-0.26)$, Bed 3 $(-0.30)$, lizard scutes $(-0.14)$ and wood $(-0.11)$. This pattern shows that the strongest differences between sublocalities are due to the beds they contain, not lateral differences along one bed, and that non-mammalian remains such as snails, hackberry seeds and wood mainly account for the differences. Bone Bed 2 (the red bed couplet) is most unlike the other beds. It preferentially contains bleached white bone and is impoverished in snails and hackberry seeds. Although the red bed couplet has fewer mammalian remains than other beds, this difference is less pronounced than the others. Beds 5 and 6 , and to some extent Bed 7, contain abundant mammalian remains, but are generally low in snails, hackberry seeds, wood and lizard scutes. In general, these sublocalities represent spatially and temporally heterogeneous depositional settings for fossils. The abundance of one type of fossil material has only a slight influence upon the occurrence of other types with it.

The final data set analyzed is a tabulation of minimum numbers of individuals for each vertebrate species (except lizards and turtles) in all sublocalities with two or more taxa. Minimum numbers of individuals for each sublocality were computed independently of other sublocalities and consequently may represent a slight overestimate of diversity and abundance in sublocalities due to vertical mixing of specimens. This overestimate is probably not large because specimens tend to move and be destroyed relatively rapidly. 
Sublocalities entirely on hillslopes (no flats) are usually not very fossiliferous and would add relatively little to sublocalities below. Low fossil abundance on these sublocalities is due to the higher slope angles and more rapid fossil movement and also to the smaller cross-sectional area of beds exposed on steep faces. These data include quadrat collections. Little bias is expected due to this inclusion since mammalian dental remains are the primary target of collectors and less dental material should be missed on sublocalities (versus quadrats) than other fossil items.

The goal of this analysis is to quantify the co-occurrence of taxa, on a larger scale than quadrats, within and between fossiliferous beds. Cluster analysis was performed to group taxa. Similarity is based on an unweighted Jaccard's coefficient and clustering was done using single linkage (Sneath and Sokal, 1973). This technique groups samples based upon co-occurrence of items using presence-absence data and ignores mutual absences (Macdonald, 1975). Clusters are linked at the value of the two most highly correlated items among the clusters (Sneath and Sokal, 1973). Fig.9 shows the clustering of taxa where 0 on the distance scale is complete similarity. The greatest similarity is shown among the most common taxa (see Table VIII). Taxa such as Hyopsodus, Hyracotherium, Haplomylus, and Diacodexis are not only widely distributed, but preferentially occur together. Groupings of taxa

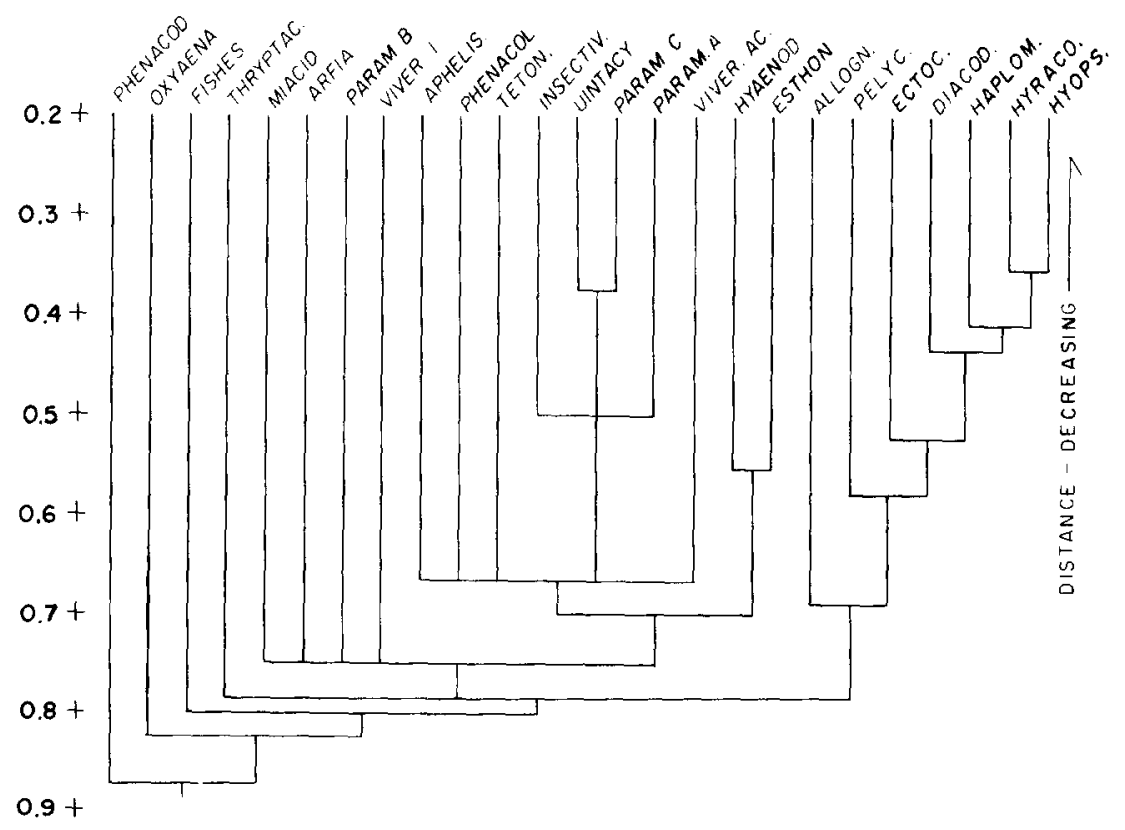

Fig.9. Cluster diagram of the most common taxa in SC-210 using Jaccard's coefficient. Clustering is based upon the mutual occurrence of taxa in surface collections from sublocalities. Taxa most often found together have the smallest distance scores. The most abundant taxa cluster together on the right, and a second group of small, possibly arboreal, taxa is shown in the center. 
TABLE VIII

Rank abundance of taxa expressed as percent of sublocalities that contain each taxon

\begin{tabular}{lrlr}
\hline & $\%$ & & $\%$ \\
\hline Hyracotherium & 63.1 & Arfia & 6.2 \\
Hyopsodus & 55.4 & Oxyaena & 6.2 \\
Haplomylus & 43.1 & Phenacodus & 6.2 \\
Diacodexis & 41.5 & Apheliscus & 4.6 \\
Ectocion & 36.9 & Insectivores & 4.6 \\
Pelycodus & 29.2 & Paramys sp. A & 4.6 \\
Allognathosuchus & 18.5 & Paramys sp. B & 4.6 \\
Esthonyx & 12.3 & Coryphodon & 3.1 \\
Paramys sp. C & 10.8 & Tetonoides & 3.1 \\
Hyaenodontids & 9.2 & Ectoganus & 1.5 \\
Uintacyon & 9.2 & Ectypodus & 1.5 \\
Fishes & 7.7 & Homogalax & 1.5 \\
Miacids & 7.7 & Miacis & 1.5 \\
Phenacolemur & 7.7 & Pachyaena & 1.5 \\
Thryptacodon & 7.7 & Viverravus acutus & \\
Viverravus sp. 1 & 7.7 & & \\
\hline
\end{tabular}

such as Uintacyon and Paramys sp. A or small hyaenodontids and Esthonyx are even more indicative of true co-occurrence since they are all less common. Many more specimens and samples would be necessary to clearly show patterns of co-occurrence, especially because some taxa are represented by only one or two specimens. Some interesting groupings do, however, occur. The crocodilian Allognathosuchus is most strongly associated with the common mammals. The common primate Pelycodus is the least associated with the common taxa. This is interesting, in that it is part of the Wasatchian immigration which includes all of the common taxa except Haplomylus and Ectocion (Rose, 1981). Ectocion was extremely abundant in the Clarkforkian, and yet it is more strongly associated than Pelycodus with the group of mammals that presumably caused its rapid decline in the Wasatchian (Rose, 1981). There appears to be a grouping of the carnivores Uintacyon and Viverravus acutus with rodents, small primates, and insectivores. The carnivorous creodonts do not fall into this group.

Co-occurrence of taxa is primarily the result of their relationship to a particular environment or habitat. Table IX shows the distribution of taxa among the various bone beds. The common taxa are found throughout the section. The most interesting point shown here is the occurrence of large, uncommon, and archaic animals only on the red bed couplet. These include Ectoganus, Pachyaena, and Coryphodon. Although Ectoganus and Pachyaena are each represented by only one specimen, it is odd that they and one of the two Coryphodon specimens found in SC-210, should all be from the red bed couplet. This, along with other facts, suggests a difference in environment between the red bed couplet and orange-gray couplets. 


\section{TABLE IX}

Occurrence of taxa in bone beds (parentheses indicate specimens which could have been derived from a bone bed above the one indicated)

\begin{tabular}{|c|c|c|c|c|c|c|c|c|c|c|c|c|c|c|c|}
\hline & \multicolumn{7}{|c|}{ Bone bed } & & \multicolumn{7}{|c|}{ Bone bed } \\
\hline & 1 & 2 & 3 & 4 & 5 & 6 & 7 & & 1 & 2 & 3 & 4 & 5 & 6 & 7 \\
\hline Hyracotherium & $x$ & $x$ & $x$ & $x$ & $x$ & $x$ & $x$ & Ectoganus & & $x$ & & & & & \\
\hline Diacodexis & $x$ & $x$ & $x$ & $x$ & $x$ & $x$ & $x$ & Pachyaena & & $x$ & & & & & \\
\hline Ectocion & $x$ & $x$ & $x$ & $x$ & $x$ & $x$ & $x$ & Miacids & & & $x$ & $x$ & $x$ & $x$ & $x$ \\
\hline Esthonyx & $x$ & $x$ & $x$ & $x$ & $x$ & $x$ & $x$ & Uintacyon & & & $x$ & $x$ & $x$ & $x$ & $x$ \\
\hline Allognathosuchus & $x$ & $x$ & $x$ & $x$ & $x$ & $x$ & $x$ & Oxyaena & & & $x$ & $x$ & $x$ & $(x)$ & $x$ \\
\hline Thryptacodon & $x$ & $x$ & $x$ & $x$ & $x$ & $x$ & $x$ & Paramys sp. A & & & $x$ & $x$ & $x$ & $x$ & \\
\hline Hyaenodontids & $x$ & & & $x$ & $x$ & $x$ & $x$ & Tetonoides & & & $x$ & $x$ & $x$ & $x$ & \\
\hline Hyopsodus & & $x$ & $x$ & $x$ & $x$ & $x$ & $x$ & Phenacolemur & & & $x$ & $x$ & $x$ & $x$ & \\
\hline Haplomylus & & $x$ & $x$ & $x$ & $x$ & $x$ & $x$ & Insectivores & & & $x$ & $(x)$ & $x$ & $(x)$ & \\
\hline Pelycodus & & $x$ & $x$ & $x$ & $x$ & $x$ & $x$ & Viverravus sp. & & & $x$ & & $x$ & $x$ & $x$ \\
\hline Fishes & & $x$ & $x$ & $x$ & $x$ & $x$ & $x$ & Apheliscus & & & $x$ & & $x$ & $(x)$ & \\
\hline Paramys sp. C & & $x$ & $x$ & & $x$ & $\hat{x}$ & $x$ & Ectypodus & & & $\hat{x}$ & & & $x$ & $(x)$ \\
\hline Phenacodus & & $x$ & $x$ & $x$ & & $x$ & & Miacis & & & $x$ & & & & \\
\hline Paramys sp. B & & $x$ & $x$ & & $x$ & $x$ & & Viverravus acutus & & & & & $x$ & $x ?$ & \\
\hline Arfia & & $x$ & & & $x$ & $x$ & $x$ & Homogalax & & & & & $x$ & & \\
\hline Coryphodon & & $x$ & & & & $x$ & $(x)$ & & & & & & & & \\
\hline
\end{tabular}

\section{Relative abundance}

Minimum numbers of individuals were calculated for all mammals, separately at first, in each sublocality. For all sublocalities with other sublocalities vertically above them, the minimum number of individuals was totaled only for individuals uniquely present there (minus those that could have been derived from above). Therefore, if a taxon was present above in one sublocality, the same element of that taxon must be found in the sublocality below for it to be counted below. This procedure assumes little or no horizontal spread of single specimens either at the time of burial or during exhumation, but gives a more conservative estimate of abundance than that used for associating taxa. Fig.10A shows the relative abundances of taxa from all surface collections. The assemblage shown is dominated by five taxa of small to medium-large body size for this fauna. Many taxa are relatively rare.

An estimate of true relative abundances can be made using the proportions of taxa found in the washed samples. It is assumed that the ratio of small sized taxa to larger, more common taxa found by washing should be equal to

Fig.10. A. Relative abundance of all mammalian taxa represented by dental remains recovered by surface prospecting. Based upon a minimum number of 300 individuals. The fauna is dominated by the small and medium-sized animals and very small animals are rare. B. Relative abundance of mammalian taxa in an unbiased surface sample after correcting for the proportion of very small taxa found in screen washed samples. In contrast to Fig. 10A, the fauna is dominated by the smallest-sized animals. 
A

RELATIVE ABUNDANCE - SURFACE

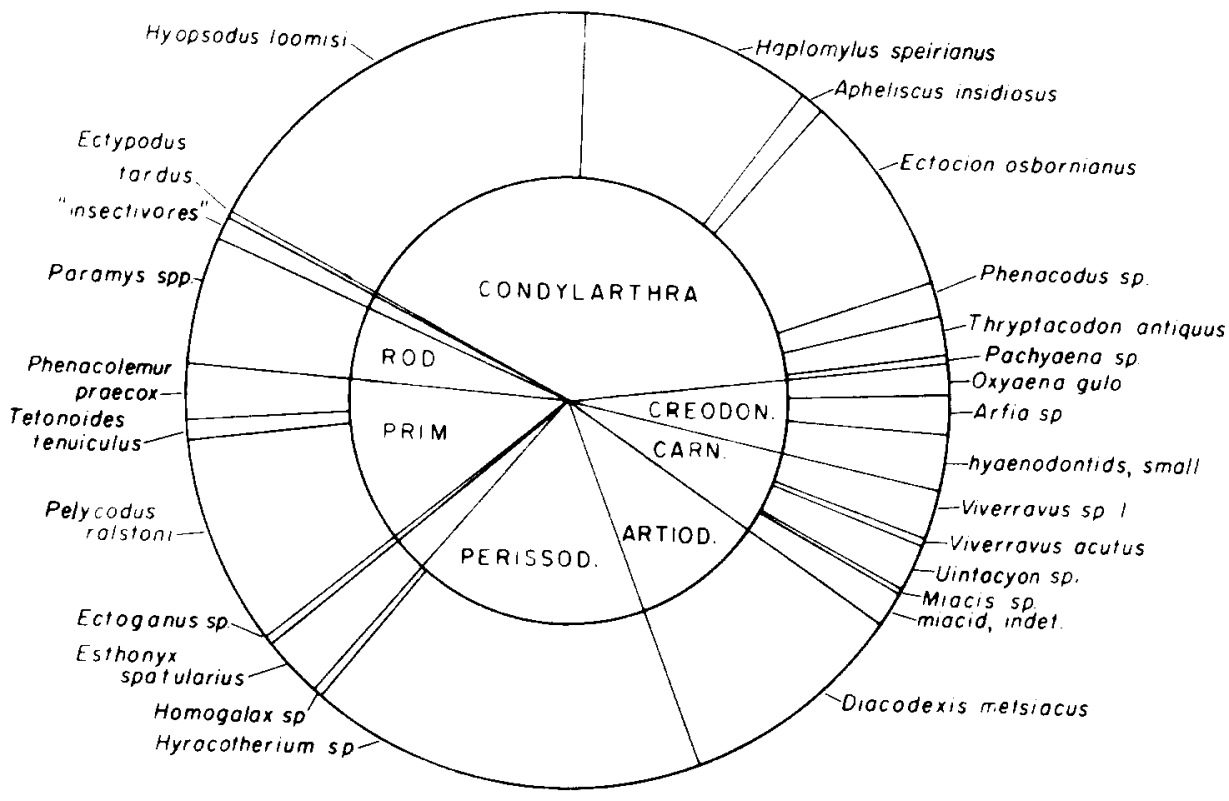

B

RELATIVE ABUNDANCE - UNBIASEO

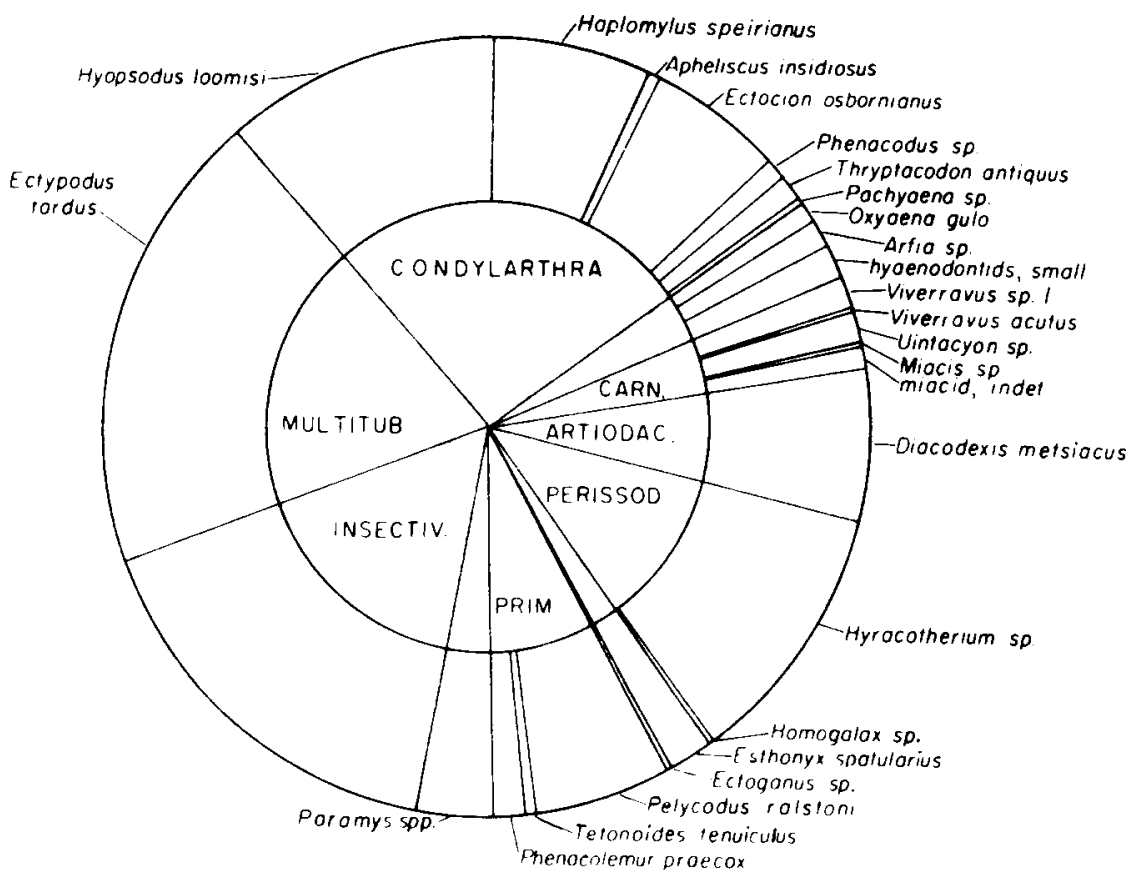


this ratio in an unbiased surface collection. The screen washed sample is not biased against small sizes (except possibly forms smaller than the screen mesh), but contains fewer individuals than the surface collection. Therefore, the proportion of individuals of small size that would have been expected in an unbiased surface collection was calculated using the relationship: $M S r=$ $M S c(M W r / M W c) . M S r$ is the expected minimum number of individuals of very small taxa ( $r=$ rare) in an unbiased surface collection; $M S c$ is the minimum number of individuals of four of the most common species from the surface collection; $M W c$ is the minimum number of individuals of the same four common taxa from the wash collection. This calculation was made for each taxon of small body size separately, based on the number of individuals of four taxa found to be common in surface and washed samples, and all other Graybullian localities. The bulk of the washing sample was taken from Wash Site $1(89 \%)$. This site is part of a pocket that appears to be primarily smaller taxa - the "A" series quadrats and sublocality XA contain few specimens of larger taxa. Therefore, the common taxa used as a basis for the calculation, Diacodexis, Haplomylus, Hyopsodus and Pelycodus are all of small size (however, they are about median for this fauna). Taxa with larger body size, such as Hyracotherium and Ectocion, are also common, however they are uncommon in the wash. The group of four common taxa is used in the calculation instead of one separate common taxon to avoid variations which might occur in the proportion of one of these taxa on the depositional horizons sampled. The calculation was made for the multituberculate Ectypodus tardus and for "insectivores" as a group. The calculated expected minimum numbers of individuals for these taxa were substituted for the respective numbers of individuals that were found by surface collecting. Based on this, a new tabulation of relative abundance for all taxa was made and this is shown in Fig.10B.

The assemblage is now shown to be dominated by these small forms. There is a more gradual drop in relative abundances from highest to lowest in the whole fauna. As in modern faunas, the tiny insectivores are quite common. Unexpectedly, Ectypodus is very common at a time in geological history when multituberculates are supposed to be uncommon and rapidly declining. While it is possible that the abundances of small forms are abnormally high due to accidents of sampling (samples taken from areas with an abnormal concentration of small forms), several things suggest this estimate of abundance is reasonable. First, surface prospecting is bound to underestimate the abundance of small taxa (but not necessarily the diversity) because small taxa are difficult to see and they are easily reburied. Secondly, Ectypodus was abundant in Wash Site 1 and it also was found in Wash Site 2 where no other identifiable teeth were found. Site 2 is in a different area, and a different stratigraphic horizon from Wash Site 1 . The insectivores found on the surface were, in at least half the cases, partly embedded in concretions and thus presented a larger target for collectors. The most common medium-sized form is Hyracotherium. The phenacodontid Ectocion is fairly common. 
Mammals that are very large for the fauna, such as Coryphodon, are rare at SC-210.

A number of taxa are missing from SC-210 that are known from the Sand Coulee area at nearly the same stratigraphic level. These include several multituberculates, a second species of Esthonyx, several creodonts, the viverravine Didymictis, several small primates, and marsupials. All of these are relatively rare, but several are well represented in localities near SC-210. These absences are probably due, in part, to inadequate sampling (i.e. too little washing). Other absences, however, must be real and represent taxa that are missing because they are extremely rare or negatively associated with the environments and taxa sampled at SC-210. Ectypodus and all "insectivores" are absent from all types of collections made on the red bed couplet.

\section{PALEOECOLOGY}

A little can be inferred about early Eocene environments based on comparison of fossils with modern species which may be similar in habit. The only botanical remains found at SC-210 were small wood fragments and Celtis seeds. No pollen grains were observed while scanning the dissolved, but untreated sediment. Modern hackberries tend to grow in more upland or high ground sites and not lowlands (MacGinitie, 1962).

All gastropod genera listed in Table VII, except Discus, have previously been noted from the Sand Coulee area (Henderson, 1935). The only specimen of the aquatic pulmonate Physa occurred on the red bed couplet. Aquatic pulmonates are commonly found in small ponds or lakes with submerged vegetation (Hanley, 1976). Modern species of Physa show a wide environmental tolerance and are found in almost all kinds of bodies of water (LaRocque, 1960). Viviparus is a common element in SC-210 and also indicates the continuing presence of water in the environment. LaRocque (1960) states that modern Viviparus are also environmentally tolerant and their presence indicates an abundant supply of minute plants and decaying animal matter on which they feed.

Hanley (1976) interprets the dominance of terrestrial gastropods in the Wasatch Formation as indicating moist, calcium-rich, lowland habitats in a deciduous forest. Oreohelix is an indicator of calcium carbonate in the environment (LaRocque, 1960). Discus is a very abundant taxon at SC-210. Modern members of this genus optimally live in humid, wet forest situations under decaying leaves and wood (LaRocque, 1960).

The abundance of lizards and the relative scarcity of turtles, crocodilians and fish all indicate a relatively dry environment. The presence and size of specimens of Amia and Lepisosteus do indicate that fairly large bodies of water (e.g., large rivers) were present in the area at some time during deposition of the sequence at SC-210. The amphibians also indicate that water bodies were at least seasonally present.

Lizards are diverse and common throughout SC-210. Most are relatively small and washing has produced specimens of juvenile individuals. Sullivan 
(1979) relates the obtuse tooth type found in many anguids to a diet of land molluscs. The abundance of both lizards and terrestrial snails at SC-210 may also be used to support such a relationship.

Early Eocene mammalian faunas are difficult to compare with modern faunas in terms of composition and habits of the members because they are not well known postcranially and have few closely related modern descendants. However, relative body size can provide some information about environment. To compare relative sizes of members of the fauna, a plot was made of the natural log of the area of lower $M_{1}$ (Fig.11). Lower $M_{1}$ has been

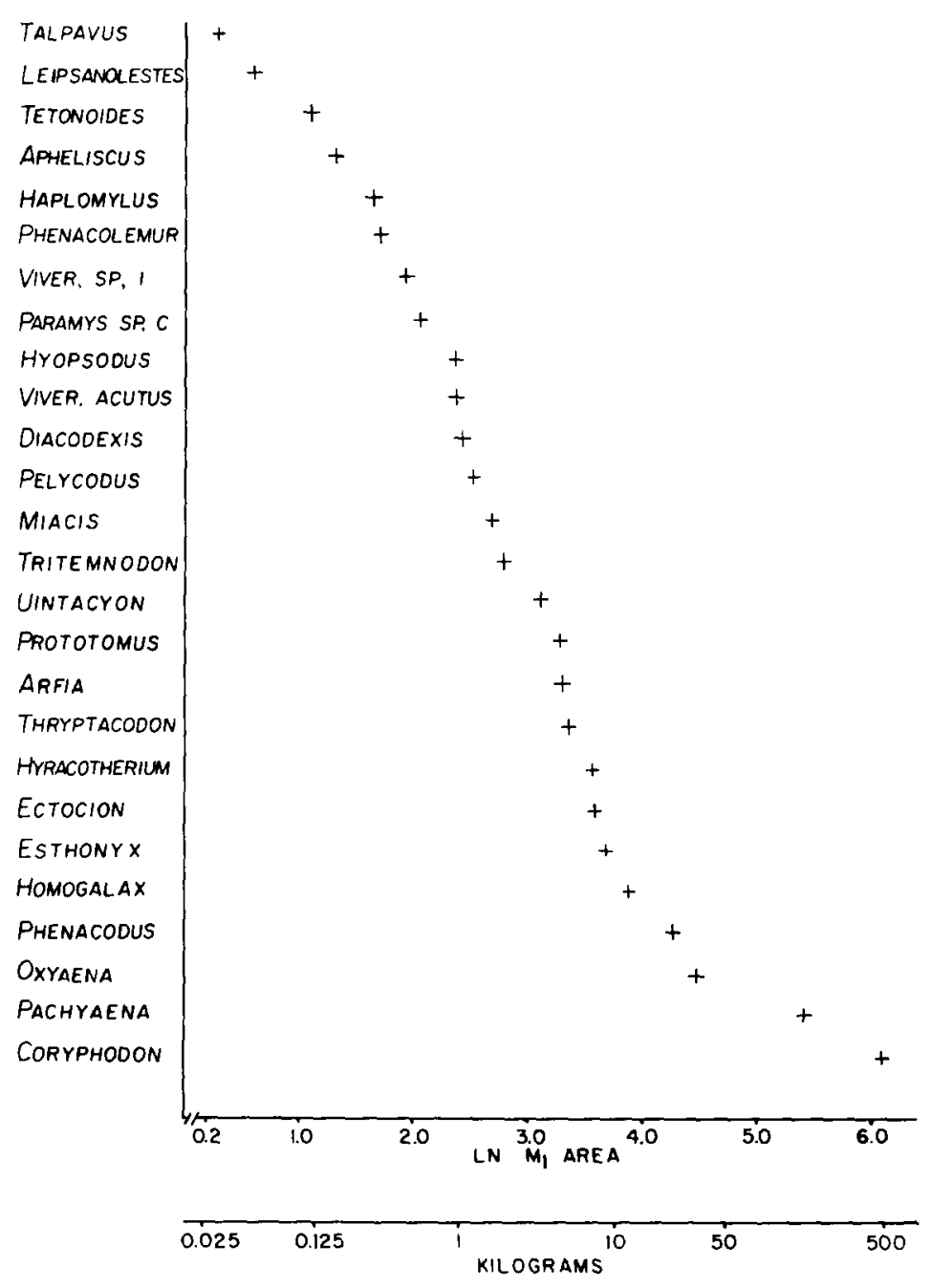

Fig.11. Distribution of tooth sizes (natural logarithm of length multiplied by width of $M_{1}$ ) of 26 mammalian genera and species in the fauna in SC-210 with their inferred body size from a regression based upon modern primates. Body size estimates are tenuous. 
found to be the least variable tooth in several groups of mammals, and is probably the best predictor of body size (Gingerich and Winkler, 1979). A regression of $M_{1}$ area versus body weight has been computed for modern primates and is included in Fig.11 (Gingerich et al., 1980a). This regression is probably accurate for the primates in the fauna and also may fit for some of the other groups since much of the fauna has a generalized dentition like that of modern primates. All body weight predictions are tenuous, and those predicted for the carnivorous mammals may well be overestimates. Several species are not included in the plot because there are no reliable estimates of $M_{1}$ size for these animals near the level of SC-210. The curve is S-shaped and shows that members of the fauna were relatively evenly spread throughout the range of body sizes, and not clustered. By grouping members into weight classes, the fauna is shown to have a large proportion of small members. This is most similar to the pattern shown in modern lowland forest faunas (Andrews et al., 1979).

\section{DISCUSSION}

Van Houten (1945) suggested that early Eocene faunas were divided into two "facies" based upon size of taxa and habitat. Larger animals are found in surface collections, which represent terrestrial habitats, and smaller animals are mainly arboreal and are found by quarrying (Van Houten, 1945). Both surface and wash samples from SC-210 demonstrate that these "faunal facies" are not distinctly separate, but that terrestrial taxa and arboreal taxa do tend to group separately. This pattern of co-occurrence can be interpreted in several ways. If these two groups of animals die and are preserved where they lived, then their habitats may have been different. It is also possible that carnivores preyed upon particular sets of taxa and the segregation in the fossil assemblage is due to the habits of different carnivores. The fact that predator remains of all sizes are preserved in the same way as herbivores does not support the latter idea.

Circumstances that were necessary for final burial and preservation of vertebrate material in SC-210 may have been unusual. Vertebrate remains occur only in dark gray mudstones, but gastropods occur in siltstones as well as mudstones. If skeletons were not buried relatively soon after death, then bone beds must represent a very short period of bone accumulation compared to the time of soil formation. Surface weathering of exposed bone would destroy skeletons in about ten years (Voorhies, 1969). It is possible that skeletons were rapidly covered by ground litter and mixed into the soil. In this case, accumulation could have occurred for many years. In either case, the event that causes the burial of a soil and the preservation of fossils, after thousands of years of non-deposition, is very likely a major flood and may be directly related to the mortality of some of the animals preserved.

Although fossils occur in sandstones in the Willwood, they are very rare compared to paleosol accumulations. This implies that little reworking of the 
flood plain by channels occurred. The absence of fossils from drab muds and silts also deserves consideration. These units may have been deposited relatively rapidly, allowing little time for animals to be incorporated, but slow enough not to cause mass mortality. Alternatively, drab muds and silts may have been unfavorable chemical environments for fossil preservation, in contrast to the A horizons of paleosols.

The only examples of non-mudstone preservation of vertebrates in SC-210 are two blocks of freshwater limestone that are weathered out of stratigraphic context on sublocality $\mathrm{YN}$.

The highly fragmented bone from SC-210 indicates that some post-mortem breakage occurred. This may be due to carnivores or just to surface weathering and trampling. Much fragmentation of bone is also possibly due to postburial compaction and microfaulting of the muds in which the fossils occur (Womochel, 1977). Although vertebrate remains are often found within calcium carbonate soil nodules, they may also become encrusted with calcium carbonate as modern weathering and exposure are occurring. Several metal surveyor's flags used to mark bone position had calcium carbonate encrusting them after several months in the ground. This encrustation probably tends to preserve more complete specimens.

The amount of bias in the relative abundance of taxa produced by surface collecting in SC-210 is much higher than that found by Bown (1979). It is possible that Wash Site 1 has an abnormal accumulation of small forms, but McKenna (1960) has also found a high proportion of multituberculates in some localities in the Four Mile fauna. Observations at other localities in the Sand Coulee area seem to confirm that small forms and especially insectivores can be very abundant. The relative abundance of rodents in the Four Mile localities is as high as that of Ectypodus in SC-210. Rodents are much rarer in SC-210 than the Four Mile fauna. This may be related to the ecological equivalence of these forms, but no good evidence is available to test this hypothesis.

Relative abundance diagrams made from fossil samples in deposits that represent long periods of bone accumulation would probably not represent standing density of mammals at any one time. If large and small mammals preserve equally well (which may not be true), then the generally higher reproductive rate of small mammals (i.e. more litters per year and faster maturation) would make them over-represented in the fossil deposit. Modern white-tailed deer and deer mice in the U.S. may have respective reproductive rates as different as 1 and 15 young per year. This difference is due mainly to the low survival rate of small mammals, and not just to greater density. To make an accurate diagram of standing abundance of fossils from such deposits it would be necessary to estimate, and compensate for, reproductive rates of fossil mammals. Unfortunately, this is not possible. However, presuming the fossils in many early Tertiary paleosol sequences are similar in their modes of accumulation, relative abundance diagrams are comparable for many areas and may provide a more consistant picture of the fauna than any single standing abundance would. 


\section{CONCLUSIONS}

Systematic surface prospecting of a mammalian locality of approximately $390 \mathrm{~m}$ by $360 \mathrm{~m}$ in the early Eocene Willwood Formation revealed a sequence of seven superjacent bone producing beds in $22 \mathrm{~m}$ of vertical stratigraphic section. The bone-producing beds are dark gray mudstones that overlie orange or red colored mudstones. These gray-over-orange or red couplets are the $\mathrm{A}$ and $\mathrm{B}$ horizons of paleosols, respectively (Bown, 1979; Bown and Kraus, 1981a). In addition to the seven prominent beds, seven other less developed soil horizons (incipient orange beds of Fig.3) were located, but no bone was associated with these paleosols.

Sixty-five topographically and stratigraphically defined sublocalities were intensively searched to recover all fossil material on the surface. Locality SC210 produced abundant remains of mammals, reptiles, snails, and hackberry seeds, and it also contains birds and amphibians. Principle components analysis comparing the abundance of fossil items in all sublocalities demonstrated that different paleosols produce different fossil assemblages. Bone Bed 2 (the red bed couplet) was most unlike the other beds and contained significantly fewer gastropods and Celtis seeds. A screen-washed sample of fresh matrix from Bone Bed 2 contained no remains of very small mammals, in contrast to bone beds associated with orange colored beds. This bed also produced the only remains of several large and archaic mammalian taxa. Other bone beds showed differences due to the content of items such as gastropods and Celtis seeds, but not due to vertebrate fossil content. No differences in assemblage composition were noticed laterally along a single bone bed, however such differences must occur over larger areas.

Minimum numbers of individuals were computed for all mammalian taxa represented by dental material and for Allognathosuchus and fishes in each sublocality. Cluster analysis of these data showed an association of the most abundant mammalian taxa, and other associations of small herbivores with small carnivores. Although larger sample sizes are needed for more reliable conclusions, these associations may reflect the similar habitat preferences of animals in different clusters or, less likely, that the accumulations are due to predators.

Screen washing of fresh matrix shows that surface collections underestimate the abundance of very small mammals. The relative abundance diagram of the larger surface collection was adjusted using the proportion of small taxa to common taxa from washed samples. This unbiased estimate, based upon minimum numbers of individuals, shows an assemblage that is numerically dominated by insectivores, Proteutheria, and the multituberculate Ectypodus tardus. The distribution of body sizes of the taxa in SC-210 is most similar to modern faunas living in lowland forests.

The condition of bone, the relative abundance of skeletal elements preserved, and the nature of the sediments all argue for a fossil assemblage that was not transported or current sorted. These paleosol assemblages may 
represent burial of bones from a single mortality event that had not yet weathered to destruction (i.e. about $10 \mathrm{yr}$. accumulation) or they may be the result of working skeletal material into the soil for hundreds or thousands of years. The almost universal presence of bone along kilometers of outcrop of paleosols may support the latter idea. If this is the case, relative abundance diagrams must be modified to reflect the population dynamics of the taxa involved before they can truly represent the standing abundances of animals in the early Eocene fauna. Tertiary faunas can probably still be validly compared in terms of abundances if the assumption is made that most flood plain paleosol accumulations are sampling the living fauna in the same way, and this assumption seems reasonable.

Locality SC-210 represents seven episodes of fossil accumulation. During Willwood time fossils can be visualized as accumulating on the soils of a very large, forested, but flat and featureless subtropical flood plain. Rivers flooded and buried soils in any particular place, on average, approximately every $5000 \mathrm{yr}$. The climate probably had seasonal wet and dry periods. Soils may have formed longer in areas farther from active river channels or during drier climatic cycles. There may have been environmental, especially vegetational differences in these older more distal areas (red beds), compared to younger areas, possibly more proximal to rivers (orange beds) and at least some members of the mammalian fauna may have preferred one or the other of these different habitats.

Paleosol sequences offer one of the best opportunities for understanding the paleoecology of mammalian faunas. The best technique for sampling such an assemblage is screen washing of fresh, unweathered matrix. This method is laborious but potentially can provide much information concerning faunal habitat preferences and relative abundance.

\section{ACKNOWLEDGEMENTS}

This study would not have been possible without the assistance and encouragement of Dr. Philip D. Gingerich, to whom I am greatly indebted. I also owe special thanks to Drs. G. R. Smith and B. H. Wilkinson for their help and advice. Dr. T. M. Bown made many suggestions about the taphonomy and geology of the study area, and his help is greatly appreciated. I thank Mr. W. Bartels, M. Bartholomew, H. Deutsch, and N. Wells for valuable assistance in the field. I am grateful to Dr. K. D. Rose for his aid with identifications of mammalian taxa and many discussions. W. Bartels, H. Deutsch, D. Krause, and G. Paulson also helped with faunal identifications. I thank W. Bartels, M. Bartholomew, C. Childress, H. Deutsch, M. Deutsch, P. Gingerich, G. Gunnell, D. Krause, S. Krause, C. Oblinger, and G. Paulson for aid in collecting at the site. This study was supported by a Turner grant from the Department of Geological Sciences, University of Michigan (to the author), and National Science Foundation grants DEB 77-13465 and DEB 80-10846 (to P. D. Gingerich). 


\section{REFERENCES}

Andrews, P., Lord, J. M. and Nesbit Evans, E. M., 1979. Patterns of ecological diversity in fossil and modern mammalian faunas. Biol. J. Linn. Soc., 11: 177-205.

Behrensmeyer, A. K., 1975. The taphonomy and paleoecology of Plio-Pleistocene vertebrate assemblages east of Lake Rudolf, Kenya. Bull. Mus. Comp. Zool., Harv. Univ., 146(10): 473-578.

Behrensmeyer, A. K., Western, D. and Dechant Boaz, D. E., 1979. New perspectives in vertebrate paleoecology from a recent bone assemblage. Paleobiology, 5(1):12-21.

Berggren, W. A., McKenna, M. C., Hardenbol, J. and Obradovich, J. D., 1978. Revised Paleogene polarity timescale. J. Geol., 86: 67-81.

Bown, T. M., 1979. Geology and mammalian paleontology of the Sand Creek facies, lower Willwood Formation (Lower Eocene), Washakie County, Wyoming. Wyo. Geol. Surv. Mem., 2: 1-151.

Bown, T. M. and Kraus, M. J., 1981a. Lower Eocene alluvial paleosols (Willwood Formation, northwest Wyoming, U.S.A.) and their significance for paleoecology, paleoclimatology, and basin analysis. Palaeogeogr., Palaeoclimatol., Palaeoecol., 34:1-30.

Bown, T. M. and Kraus, M. J., 1981b. Vertebrate fossil-bearing paleosol units (Willwood Formation, Lower Eocene, northwest Wyoming, U.S.A.): Implications for taphonomy, biostratigraphy, and assemblage analysis. Palaeogeogr., Palaeoclimatol., Palaeoecol., 34: $31-56$.

Braunagel, L. H. and Stanley, K. O., 1977. Origin of variegated redbeds in the Cathedral Bluffs Tongue of the Wasatch Formation (Eocene), Wyoming. J. Sediment. Petrol., 47(3): 1201-1219.

Dodson, P., 1973. The significance of small bone in paleontological interpretation. Univ. Wyo. Contrib. Geol., 12(1): 15-19.

Fisher, D. C., 1981. Crocodilian scatology, microvertebrate concentrations, and enamelless teeth. Paleobiology, 7(2): 262-275.

Gingerich, P. D., 1976a. Paleontology and phylogeny: patterns of evolution at the species level in early Tertiary mammals. Am. J. Sci., 276: 1-28.

Gingerich, P. D., 1976b. Cranial anatomy and evolution of Early Tertiary Plesiadapidae (Mammalia, Primates). Univ. Mich. Pap. Paleontol., 15: 1-141.

Gingerich, P. D., 1980. Evolutionary patterns in Early Cenozoic mammals. Annu. Rev. Earth Planet. Sci., 8: 407-424.

Gingerich, P. D. and Gunnell, G. F., 1979. Systematics and evolution of the genus Esthonyx Mammalia, Tillodontia) in the early Eocene of North America. Contrib. Mus. Paleontol., Univ. Mich., 25(7): 125-153.

Gingerich, P. D. and Simons, E. L., 1977. Systematics, phylogeny, and evolution of early Eocene Adapidae (Mammalia, Primates) in North America. Contrib. Mus. Paleontol., Univ. Mich., 24(22): 245-279.

Gingerich, P. D. and Winkler, D. A., 1979. Patterns of variation and correlation in the dentition of the red fox, Vulpes vulpes. J. Mammal., 60(4):691-704.

Gingerich, P. D., Smith, B. H. and Rosenberg, K., 1980a. Patterns of allometric scaling in the primate dentition and prediction of body size from tooth size. (Abstr.). Am. J. Phys. Anthropol., 52:321-322.

Gingerich, P. D., Rose, K. D. and Krause, D. W., 1980b. Early Cenozoic mammalian faunas of the Clark's Fork Basin-Polecat Bench area, northwestern Wyoming. In: Early Cenozoic Paleontology and Stratigraphy of the Bighorn Basin, Wyoming. Univ. Mich. Pap. Paleontol., 24: 51-68.

Hanley, J. H., 1976. Paleosynecology of nonmarine Mollusca from the Green River and Wasatch Formations (Eocene), southwestern Wyoming and northwestern Colorado. In: R. W. Scott and R. West (Editors), Structure and Classification of Paleocommunities. Dowden, Hutchinson and Ross, Stroudsburg, PA, pp. 235-261.

Henderson, J., 1935. Fossil non-marine Molluska of North America. Geol. Soc. Am., Spec. Pap. 3, 313 pp. 
LaRocque, A., 1960. Molluscan faunas of the Flagstaff Formation of central Utah. Geol. Soc. Am. Mem., 78: 1-100.

MacDonald, K. B., 1975. Quantitative community analysis: recurrent group and cluster techniques applied to the fauna of the Upper Devonian Sonyea Group, New York, J. Geol., 82: 473-499.

MacGinitie, H. D., 1962. The Kilgore flora. A late Miocene flora from northern Nebraska. Univ. Calif. Publ. Geol. Sci., 35(2): 67-158.

Mackin, J. H., 1937. Erosional history of the Big Horn Basin, Wyoming. Geol. Soc. Am. Bull., 48: 813-894.

McKenna, M. C., 1960. Fossil Mammalia from the early Wasatchian Four Mile fauna, Eocene of northwest Colorado. Univ. Calif. Publ. Geol. Sci., 37: 1-130.

McPherson, J. G., 1980. Genesis of variegated redbeds in the fluvial Aztec Siltstone (Late Devonian), Southern Victoria Land, Antarctica. Sediment. Geol., 27(1980): 119-142.

Mellett, J. S., 1974. Scatological origin of microvertebrate fossil accumulations. Science, 185: 349-350.

Mohr, E. C. J. and Van Baren, F. A., 1954. Tropical Soils. Interscience, New York, NY, $498 \mathrm{pp}$.

Neasham, J. W. and Vondra, C. F., 1972. Stratigraphy and petrology of the lower Eocene Willwood Formation, Bighorn Basin, Wyoming. Geol. Soc. Am. Bull., 83: 2167-2180.

Olson, E. C., 1962. Late Permian terrestrial vertebrates, U.S.A. and U.S.S.R. Trans. Am. Philos. Soc., 52(2): 1-224.

Rose, K. D., 1980. Clarkforkian Land Mammal Age; revised definition, zonation, and tentative intercontinental correlations. Science, 208: 744-746.

Rose, K. D., 1981. The Clarkforkian Land-Mammal Age and mammalian faunal composition across the Paleocene--Eocene boundary. Univ. Mich. Pap. Paleontol., 26:1-197.

Shotwell, J. A., 1963. The Juntura Basin: studies in earth history and paleoecology. Trans. Am. Philos. Soc., 53(1): 1-77.

Sneath, P. and Sokal, R., 1973. Numerical Taxonomy. W. H. Freeman, San Francisco, CA, 573 pp.

Sullivan, R. M., 1979. Revision of the Paleocene genus Glyptosaurus (Reptilia, Anguidae). Bull. Am. Mus. Nat. Hist., 163(1): 1-72.

Van Houten, F. B., 1944. Stratigraphy of the Willwood and Tatman formations in northwestern Wyoming. Geol. Soc. Am. Bull., 55: 165--210.

Van Houten, F. B., 1945. Review of latest Paleocene and early Eocene mammalian faunas. J. Paleontol., 19(5): 421-461.

Van Houten, F. B., 1968. Iron oxides in red beds. Geol. Soc. Am. Bull., 79: 399-416.

Van Houten, F. B., 1973. Origin of red beds: A review - 1961-1972. Annu. Rev. Earth Planet. Sci., 1: 39-61.

Voorhies, M. R., 1969. Taphonomy and population dynamics of an early Pliocene vertebrate fauna, Knox County, Nebraska. Univ. Wyo. Contrib. Geol., Spec. Pap., 1, 69 pp.

Voorhies, M. R., 1970. Sampling difficulties in reconstructing late Tertiary mammalian communities. Proc. North American Paleont. Conv., 1969: 454-468.

Winkler, D. A., 1980. Taphonomy and faunal sampling in the Early Wasatchian of the Clark's Fork Basin, Wyoming. In: Early Cenozoic Paleontology and Stratigraphy of the Bighorn Basin, Wyoming. Univ. Mich. Pap. Paleontol., 24: 81-85.

Womochel, D. R., 1977. Taphonomy and Paleoecology of the Slaton Local Fauna (Pleistocene, Texas). Thesis, Texas Tech. Univ. (unpublished). 